\title{
Volume transport and mixing of the Faroe Bank Channel overflow from one year of moored measurements
}

\author{
Jenny E. Ullgren ${ }^{1}$, Elin Darelius ${ }^{2}$, and Ilker Fer ${ }^{2}$ \\ ${ }^{1}$ Nansen Environmental and Remote Sensing Center, Bergen, Norway \\ ${ }^{2}$ Geophysical Institute, University of Bergen and Bjerknes Centre for Climate Research, Bergen, Norway \\ Correspondence to: Ilker Fer (ilker.fer@uib.no)
}

Received: 26 August 2015 - Published in Ocean Sci. Discuss.: 7 October 2015

Revised: 11 February 2016 - Accepted: 3 March 2016 - Published: 15 March 2016

\begin{abstract}
One-year long time series of current velocity and temperature from eight moorings deployed in the Faroe Bank Channel (FBC) are analysed to describe the structure and variability of the dense overflow plume on daily to seasonal timescales. Mooring arrays were deployed in two sections: located $25 \mathrm{~km}$ downstream of the main sill, in the channel that geographically confines the overflow plume at both edges (section C), and $60 \mathrm{~km}$ further downstream, over the slope (section $\mathrm{S}$ ). At section $\mathrm{C}$, the average volume transport of overflow waters $\left(<3{ }^{\circ} \mathrm{C}\right)$ from the Nordic Seas towards the Iceland Basin was $1.3 \pm 0.3 \mathrm{~Sv}$; at section $\mathrm{S}$, transport of modified overflow water $\left(<6^{\circ} \mathrm{C}\right)$ was $1.7 \pm 0.7 \mathrm{~Sv}$. The volume transport through the slope section was dominated by mesoscale variability at 3-5-day timescales. A simplified view of along-path entrainment of a gravity current may not be accurate for the FBC overflow. As the plume proceeds into the stratified ambient water, there is substantial detrainment from the deeper layer (bounded by the $3{ }^{\circ} \mathrm{C}$ isotherm), of comparable magnitude to the entrainment into the interfacial layer (between the 3 and $6{ }^{\circ} \mathrm{C}$ isotherms). A time series of gradient Richardson numbers suggests a quiescent plume core capped by turbulent near bottom and interfacial layers in the channel. At section $\mathrm{S}$, in contrast, the entire overflow plume is turbulent. Based on a two-layer heat budget constructed for the overflow, time mean vertical diffusivities across the top of the bottom layer and across the interfacial layer were $(30 \pm 15) \times 10^{-4}$ and $(120 \pm 43) \times 10^{-4} \mathrm{~m}^{2} \mathrm{~s}^{-1}$, respectively.
\end{abstract}

\section{Introduction}

Cold waters that flow from intermediate levels in the Nordic Seas into the North Atlantic must cross the shallow Greenland-Scotland Ridge. Overflows occur both across the Iceland-Faroe Ridge and the Wyville Thomson Ridge, but the densest overflow plumes are those passing through the deepest gaps in the Greenland-Scotland Ridge, namely the Denmark Strait and the Faroese channels (Hansen and Østerhus, 2000; Saunders, 2001). The water mass transformation that occurs as the overflows mix with the overlying Atlantic waters plays an important role in determining the thermohaline composition of North Atlantic Deep Water (Dickson and Brown, 1994; van Aken, 2007). Here, we report on measurements of the overflow from the Faroe Bank Channel (FBC).

The FBC is a narrow channel with steep side walls (Fig. 1) The primary sill, where the channel is at its narrowest and shallowest, is about $15 \mathrm{~km}$ wide and $840 \mathrm{~m}$ deep. Approximately $95 \mathrm{~km}$ north-west of the sill, where the channel is wider and the sides less steep, there is a second sill of about $850 \mathrm{~m}$ depth (Beaird et al., 2012). The overflow from the Nordic Seas enters the FBC from the Faroe-Shetland Channel in the east and flows through the channel towards the north-west; we use "upstream" and "downstream" hereafter in the sense of the plume flow. The overflow takes the form of a well-mixed bottom layer, overlaid by a stratified interfacial layer (Fer et al., 2010). After passing through the channel, the flow widens from about $10 \mathrm{~km}$ at the primary sill to about $30-40 \mathrm{~km}$ on the slope after the secondary sill (Duncan et al., 2003; Beaird et al., 2013). Beyond this point, the flow splits into two branches: a deep one that reaches depths exceeding $1000 \mathrm{~m}$, containing the densest part of the plume 


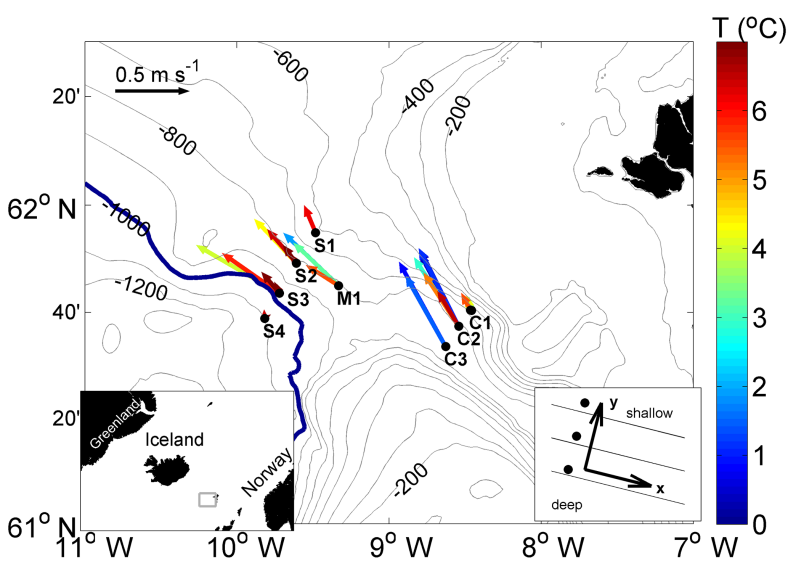

Figure 1. Map of the study region with the mooring positions (black dots) and mean current vectors from selected levels (75, 100, 150, 200,250 , and $300 \mathrm{~m}$ above the seabed) at each site, colour-coded by mean temperature from the same depth level (colour scale in ${ }^{\circ} \mathrm{C}$ on the right). Depth contours in grey are shown every $100 \mathrm{~m}$ with the $1000 \mathrm{~m}$ isobath bold, black. Insets show (left) the location of the study area and (right) the orientation of the coordinate system with respect to the mooring arrays.

and about $2 / 3$ of the total volume transport, and a shallower branch along the slope of the Iceland-Faroe Ridge at intermediate depths (Beaird et al., 2013).

The waters feeding the overflow are composed of cold, low-salinity water masses: Norwegian Sea Deep Water and Norwegian Sea Arctic Intermediate Water, both with temperatures close to or below $0{ }^{\circ} \mathrm{C}$ (e.g. Hansen and Østerhus, 2000; Fogelqvist et al., 2003). Near the sill, the overflow is typically defined as water colder than $3{ }^{\circ} \mathrm{C}$ (e.g. Borenäs and Lundberg, 1988; Hansen and Østerhus, 2007). This temperature threshold gives similar values of height and width of the overflow plume as selecting the quasi well-mixed bottom layer from temperature or salinity profiles (Duncan et al., 2003). The resulting estimate of volume transport of $1.6 \mathrm{~Sv}$ $\left(1 \mathrm{~Sv} \equiv 10^{6} \mathrm{~m}^{3} \mathrm{~s}^{-1}\right.$ ) computed from shipboard observations (Duncan et al., 2003) agrees very well with the 10-year average for the period 1995-2005 of 1.7 Sv based on moored acoustic Doppler current profilers (ADCPs) and temperature sensors (Hansen and Østerhus, 2007).

Along its path through the $\mathrm{FBC}$, the plume entrains the overlying warmer and more saline Atlantic Water, and attains higher temperatures downstream (Saunders, 1990; Mauritzen et al., 2005). Upon exiting the channel, the plume also encounters low-salinity, low-oxygen Intermediate Water from the Iceland Basin which mixes into the interfacial layer above the plume and contributes to the water mass mixture from the FBC that eventually forms a part of the North Atlantic Deep Water (Ullgren et al., 2014).

The overflow through the channel is energetic, with a longterm average velocity at the sill of up to $120 \mathrm{~cm} \mathrm{~s}^{-1}$ (Hansen and Østerhus, 2007). The plume accelerates as it descends along the deepening topography, and maximum overflow velocity is found downstream of the sill (close to $9^{\circ} \mathrm{W}$; Fer et al., 2010). The swift flow is associated with high levels of turbulence and a region of intense mixing (e.g. Fer et al., 2010). The secondary sill, where the plume thins significantly, is observed to be the most significant location in terms of mixing and water mass transformation (Beaird et al., 2012, 2013).

Currents and temperatures in the region downstream of the sill vary strongly on timescales of a few days (Geyer et al., 2006), reflected in high variability of the sea surface height field (Høyer and Quadfasel, 2001). The dense overflow takes the form of a train of 100-200 m thick boluses of cold water moving along the slope at periods of 2.5-6 days (Darelius et al., 2011). The cold water domes are associated with energetic mesoscale oscillations in the velocity field that extend throughout the water column and are linked to a wave pattern in sea surface height (Darelius et al., 2013). Guo et al. (2014) propose that these mesoscale eddies are caused by baroclinic instabilities of the overflow plume.

Because of its important role in large-scale circulation, carrying one-third of the total volume of dense overflows from the Nordic Seas into the North Atlantic, the FBC overflow has garnered scientific interest for many decades. Hansen and Østerhus (2000) compiled a number of volume transport estimates for the FBC overflow from the literature, and their summary was more recently reviewed and augmented by Kanzow and Zenk (2014). Several other studies have dealt with aspects of the overflow such as friction and mixing (e.g. Duncan et al., 2003; Borenäs and Lundberg, 2004; Mauritzen et al., 2005; Fer et al., 2010), presenting additional transport estimates. The overflow transport is continuously monitored by moored instruments at the sill section, where at least one upward-looking ADCP mooring in the centre of the channel has been maintained since 1995 (see Hansen and Østerhus, 2007). Other work on the FBC overflow has often been based on hydrographic sections, sometimes combined with current measurements. Some studies have used e.g. short-term moorings (Dooley and Meincke, 1981) or gliders (Beaird et al., 2013). Aside from the FBC sill mooring (Hansen and Østerhus, 2007), which provides one of the world's few long-term moored time series of a deep branch of the meridional overturning circulation, mooring measurements of the FBC overflow of more than a few months' duration are rare (e.g. Saunders, 1990; Darelius et al., 2011). In particular, few long-term observations have been made downstream of the sill, and none of them covers the whole vertical and lateral extent of the plume.

This study is based on the first mooring measurements to cover the full width and height of the plume for a whole year, simultaneously by two arrays, one in the channel and a second one over the Iceland-Faroe slope. These mooring data were first presented by Darelius et al. (2015), who investigated variations in the strength and periodicity of mesoscale 


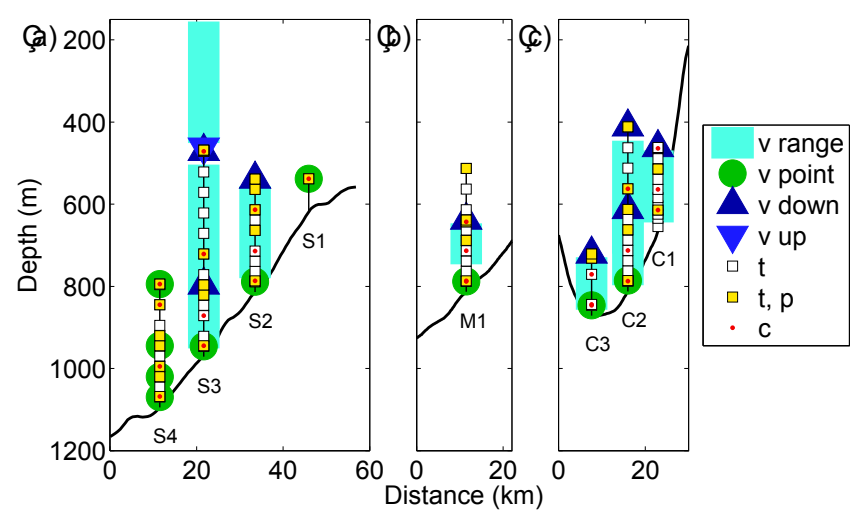

Figure 2. Mooring arrays: (a) section S, (b) mooring M1, and (c) section C. Each section is viewed looking downstream (southernmost mooring on the left). Sensors for temperature, pressure, conductivity, point velocity, as well as the range covered by the upward- and downward-oriented acoustic velocity profilers, are indicated.

oscillations. In this paper we take a broader view and address mainly the mean hydrographic and velocity characteristics of the overflow plume, its stability, mixing, and transport.

\section{Data and methods}

Data were collected in the Faroe Bank Channel overflow region using eight bottom-anchored moorings, in the period between 28 May 2012 and 5 June 2013 (Fig. 1). The "Channel" (C) mooring array was located $25 \mathrm{~km}$ downstream of the sill in the FBC, and the "Slope" (S) array a further $60 \mathrm{~km}$ west where the plume exits the narrow confines of the channel. Between the two sections, a single mooring, M1, was located $16 \mathrm{~km}$ upstream of section $\mathrm{S}$ along the main path of the plume. The horizontal separation between moorings was $7-8 \mathrm{~km}$ at section $\mathrm{C}$ and $10-12 \mathrm{~km}$ at section $\mathrm{S}$.

The moorings were equipped with temperature recorders (Sea-Bird Electronics, SBE39 and SBE56), conductivitytemperature-pressure recorders (SBE37, Microcats), Anderaa current meters (RCM7/8), a Nortek current meter (Aquadopp), and ADCPs (RD-Instruments 75/150/300 kHz Workhorse, Anderaa $600 \mathrm{kHz}$ RDCP, and Nortek Continental). Instrumentation and location of the moorings are listed in Appendix A1 and Table A1, and a schematic of the mooring array design is shown in Fig. 2. The sampling rate was $15 \mathrm{~s}$ for SBE56s, $5 \mathrm{~min}$ for SBE37s and SBE39s, 5-60 min for ADCPs, $1 \mathrm{~h}$ for recording current meters (RCMs), and $20 \mathrm{~min}$ for the Aquadopp. Three RDI $300 \mathrm{kHz}$ ADCPs located at the core of the plume (at moorings C2, M1, and S3) and vertically positioned in the interfacial layer were set to sample for a shorter duration (3-4 months) at high resolution in time and in the vertical to study mixing processes, to be presented elsewhere. The high-frequency ADCPs are included in mooring descriptions for completeness; however, they are excluded when generating the gridded fields (see below), because the vertical extents they ensonified were also covered by lower-frequency ADCPs which recorded for the entire deployment. Here we report the hourly averaged data.

The coordinate system for each mooring is aligned with the orientation of the mooring section, so that the $x$ axis is perpendicular to the section and the $y$ axis parallel to the section, pointing upslope (see right inset in Fig. 1). The angle of rotation $(\beta)$ is 34 and $31^{\circ}$ (clockwise, around the $z$ axis) for the $\mathrm{C}$ and $\mathrm{S}$ arrays, respectively.

The position of an individual mooring element relative to the anchor varies with the current and drag on the mooring. Time series of the vertical position and tilt of the instruments were calculated using the measured currents (hourly mean values) and the Mooring Design and Dynamics software (MDD; Dewey, 1999), which calculates the behaviour of a mooring in a given three-dimensional sheared current by balancing the forces acting on the mooring. The results compared well with the available pressure measurements. Statistics and further details regarding mooring pulldown and instrument tilt are given in Appendix A2. Hourly velocity and temperature records at corrected depths were then linearly interpolated to $1 \mathrm{~m}$ vertical resolution.

During the mooring deployment cruise on board RV Håkon Mosby between 26 May and 14 June 2012, a total of 146 CTD profiles were collected; see Ullgren et al. (2014). Cruise measurements were used to verify mooring temperature, salinity, and velocity data. The moored $T-S$ data showed a tight relationship between temperature $(T)$ and potential density anomaly $\left(\sigma_{\theta}\right)$. Data from all moored $T-S$ sensors were fitted to a third-degree polynomial, $\sigma_{\theta}=-(4.7 \times$ $\left.10^{-4}\right) T^{3}+\left(4.9 \times 10^{-4}\right) T^{2}-\left(4.52 \times 10^{-2}\right) T+28.0536$ (root mean square error $0.034 \mathrm{~kg} \mathrm{~m}^{-3}$ ). This allows density to be inferred from temperature measurements alone, which is desirable given the better coverage by the temperature sensors. The relation was not significantly different using monthly subsets of the data.

Temperature records are used to identify different layers in the water column. Following e.g. Hansen and Østerhus (2007) and Mauritzen et al. (2005), we use the level of the $3^{\circ} \mathrm{C}$ isotherm as a delimiter of overflow water at array $\mathrm{C}$. (Bottom water with temperature $<0.3{ }^{\circ} \mathrm{C}$ - the stricter definition of overflow used by Hansen et al. (2001) - will be referred to as very cold water.) The overflow water found further downstream is diluted by entrained warmer water; it will be referred to as modified overflow water and delineated by the $6{ }^{\circ} \mathrm{C}$ isotherm (cf. Darelius et al., 2015; Guo et al., 2014). The Atlantic Water of the upper layer is defined by a temperature of $\geq 8^{\circ} \mathrm{C}$, while waters with temperature $6^{\circ} \mathrm{C}<T<8^{\circ} \mathrm{C}$ will be referred to as Intermediate Water.

Volume transports through the channel and slope sections were determined from velocity and temperature data as described in Appendix B and in Sect. 4. 

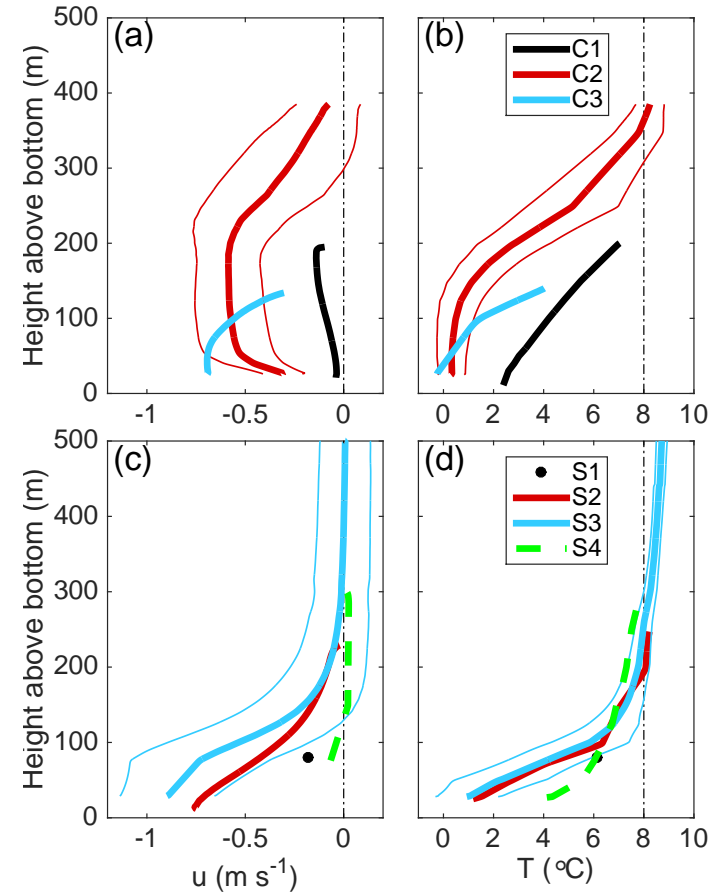

Figure 3. Mean vertical profiles of along-stream velocity $u$ (left; $\mathbf{a}$, c) and temperature (right; b, d) from the moorings in the $\mathrm{C}$ array (top; a, b) and the $\mathrm{S}$ array (bottom; c, d). Time-average profiles over the whole deployment are shown as bold lines, and 1 standard deviation from the mean as thin lines, shown for one mooring in each array $(\mathrm{C} 2, \mathrm{~S} 3)$. Thin black dash-dotted lines mark $0 \mathrm{~m} \mathrm{~s}^{-1}$ and $8{ }^{\circ} \mathrm{C}$, respectively. Only levels from which data are available at least $70 \%$ of the time are included.

\section{Average conditions}

\subsection{Thermal structure of the plume}

The dense overflow plume was thicker and colder at the channel mooring section than at the downstream section (Figs. 3 and 4). The bottom layer at the southernmost mooring in array $\mathrm{C}(\mathrm{C} 3)$ was the coldest, with a mean temperature at $26 \mathrm{~m}$ above bed (mab) of $-0.3{ }^{\circ} \mathrm{C}$ over the 1-year deployment. However, although the very cold water occasionally reached up to 140 mab at mooring C3, it was mostly present only as a thin layer. Between 30 and 100 mab temperatures increased sharply where the bottom layer was capped by strong stratification. The overflow water was generally contained within the bottom $120 \mathrm{~m}$.

In the centre of section $\mathrm{C}$, at mooring $\mathrm{C} 2$, the plume was thicker. The presence of very cold water was not as frequent as at $\mathrm{C} 3$ - only about $60 \%$ of the time even at the deepest level - but overflow water on average occupied the lower $200 \mathrm{~m}$ of the water column (Fig. 3). Above about $50 \mathrm{mab}$, the mean temperature at mooring $\mathrm{C} 2$ was thus colder than at $\mathrm{C} 3$.

The northernmost mooring $(\mathrm{C} 1)$ in array $\mathrm{C}$ was located outside the main path of the plume; very cold water occurred
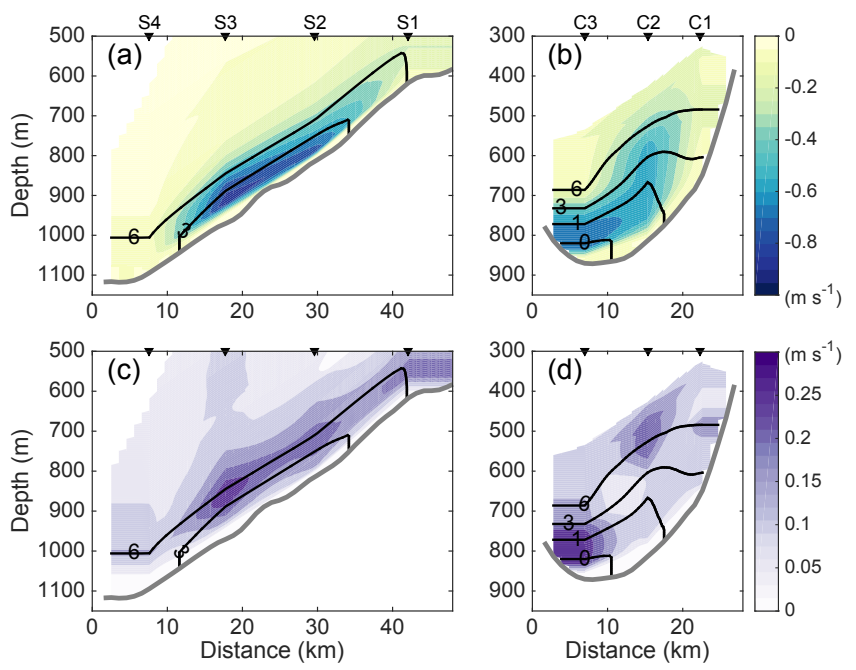

Figure 4. Cross-sectional distribution of along-stream velocity $u$ $\left(\mathrm{m} \mathrm{s}^{-1}\right)$, in colour, with average isotherms $\left({ }^{\circ} \mathrm{C}\right)$ overlaid as black contours. Time-average $(\mathbf{a}, \mathbf{b})$ and standard deviation $(\mathbf{c}, \mathbf{d})$ of daily data over the common period 30 May 2012-17 January 2013 when complete records exist at both sections: $(\mathbf{a}, \mathbf{c})$ section $\mathrm{S}$ and (b, d) section $\mathrm{C}$.

here only $<5 \%$ of the time. When present, the overflow covered up to about $100 \mathrm{~m}$ from the seabed; however, $30 \%$ of the time no overflow was recorded.

At mooring array $\mathrm{S}$, the plume was thinner and warmer than at $\mathrm{C}$, even in the bottom layer. Very cold water occurred only occasionally in the deepest layer at the two central moorings S2 and S3. At S2, the plume water $\left(T<3{ }^{\circ} \mathrm{C}\right)$ reached up to about $60 \mathrm{mab}$, overlain by a $40 \mathrm{~m}$ thick interfacial layer. At S3, the bottom and the interfacial layer were equally thin. Above the interfacial layer there was a 100$200 \mathrm{~m}$ layer of intermediate water, and Atlantic Water was found above about 200-300 mab. The water column structure at mooring S4, $14 \mathrm{~km}$ further south-west, was markedly different as this southernmost mooring in the $\mathrm{S}$ array was located outside the plume. Overflow water was measured only about $20 \%$ of the time at the deepest level, coinciding with eddy activity, while intermediate water took up a large part of the water column at $\mathrm{S} 4$, occasionally reaching the bottom.

\subsection{Velocity characteristics}

The mean current in the near-bottom layer was directed towards north-northwest at section $\mathrm{C}$ and turned more towards west-northwest at section $\mathrm{S}$ (Fig. 1). The average current was in this along-stream direction throughout the part of the water column occupied by the cold, dense plume and the interfacial layer.

The maximum plume velocity was found in the bottom $50 \mathrm{~m}$ at mooring array $\mathrm{S}$, where the time-average velocity perpendicular to the mooring section $(u$; see Sect. 2$)$ reached $90 \mathrm{~cm} \mathrm{~s}^{-1}$ (mooring S3; see Fig. 3). Similar but somewhat 


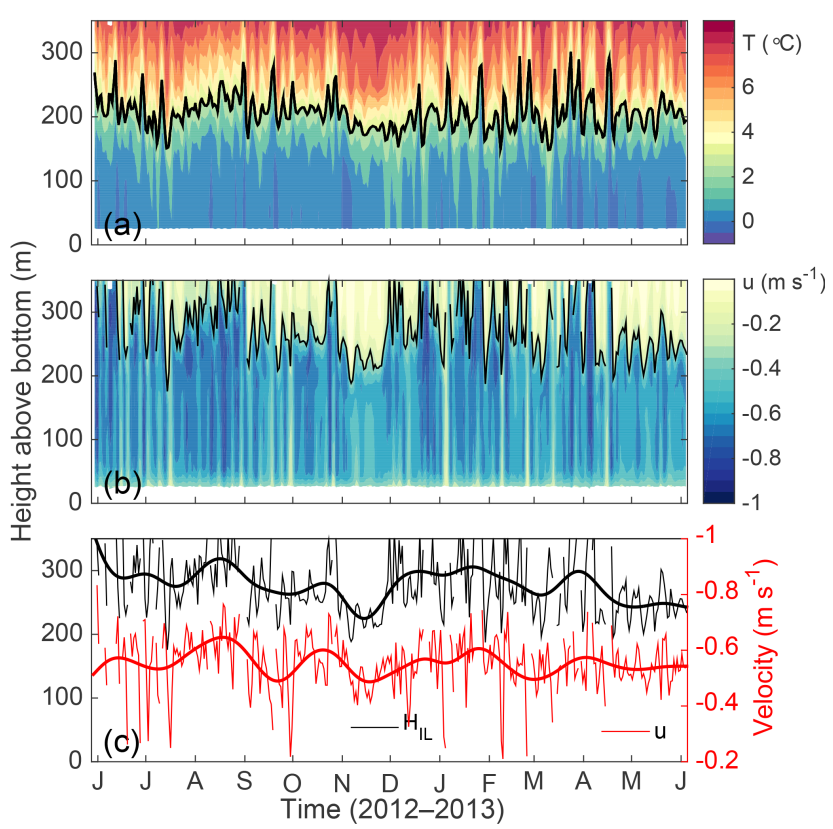

Figure 5. Time-height plots of daily (a) temperature $\left({ }^{\circ} \mathrm{C}\right)$ and (b) $u$ velocity $\left(\mathrm{ms}^{-1}\right)$ from mooring $\mathrm{C} 2$. The bold black line in (a) marks the $3{ }^{\circ} \mathrm{C}$ isotherm, and the thin black line in (b) is the kinematic interface height $H_{\mathrm{IL}}$. (c) Time series of daily (thin) and 3-week lowpassed (bold) $H_{\mathrm{IL}}$ (black) and the plume velocity (red) averaged within $H_{\mathrm{IL}}$.

weaker velocities occurred at mooring $\mathrm{C} 3$. The thickness of the maximum velocity layer, in contrast, was significantly larger at the upstream array C. Defined as the height where the along-stream velocity $u$ is reduced to half of the maximum velocity of that mooring velocity profile, the "kinematic interface height" (Hansen and Østerhus, 2007), $H_{\mathrm{IL}}$, was $220 \mathrm{~m}$ at section $\mathrm{C}$ compared to $110 \mathrm{~m}$ at $\mathrm{S}$ (see Figs. 5 and 6). The thinning of the plume with distance from the sill was reflected in both velocity and temperature profiles (Fig. 3). The height above bed of the $3{ }^{\circ} \mathrm{C}$ isotherm was similar to $H_{\mathrm{IL}}$ and correlated with it over timescales longer than 1 day, as previously observed by Hansen and Østerhus (2007).

The high-velocity core of the plume was also faster but thinner at the southern side of the $\mathrm{C}$ array. Long-term mean velocities were thus higher at mooring $\mathrm{C} 3$ than $\mathrm{C} 2$, while the opposite was true for the thickness of the high-velocity layer. This is consistent with observations by Hansen and Østerhus (2007) showing a northward decrease in velocity and an increase in plume thickness across a section at the sill in the FBC ( $\sim 25 \mathrm{~km}$ upstream of our measurements). At the $\mathrm{S}$ array the velocities were similarly higher at $\mathrm{S} 3$ than at $\mathrm{S} 2$, but no southward thinning of the plume was observed; see Fig. 4.

Although high instantaneous current velocities occurred at intermediate and upper levels, the flow above the plume was characterized by oscillations and frequent reversals, resulting in weak mean flows (Figs. 1 and 3). The varying upper layer currents contribute to modulating the period of

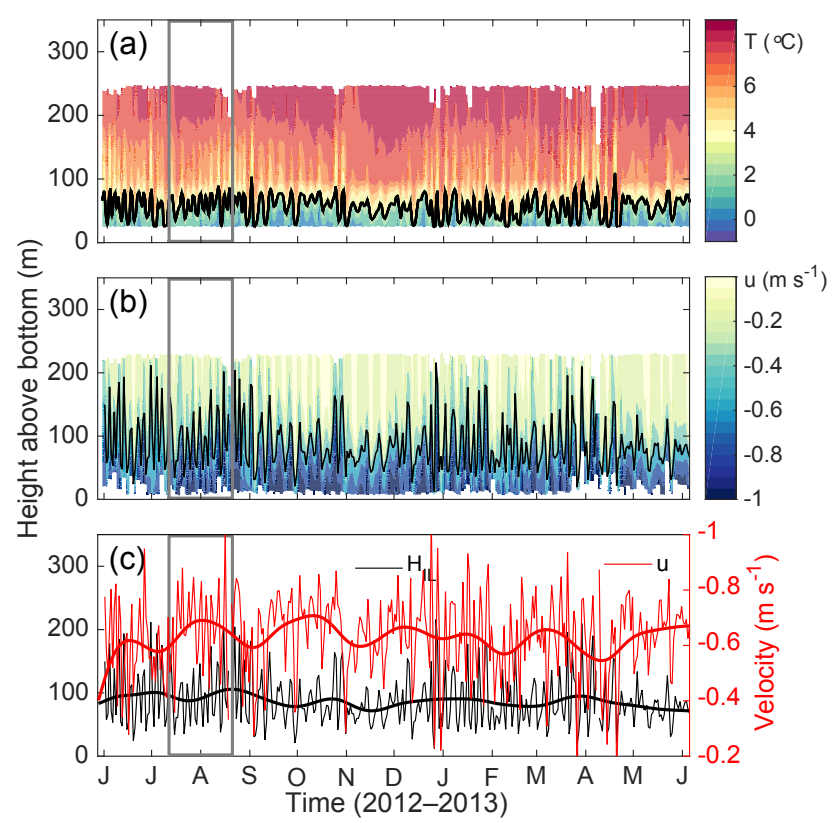

Figure 6. As Fig. 5 but for mooring S2. The grey boxes mark the time period shown in Fig. 11.

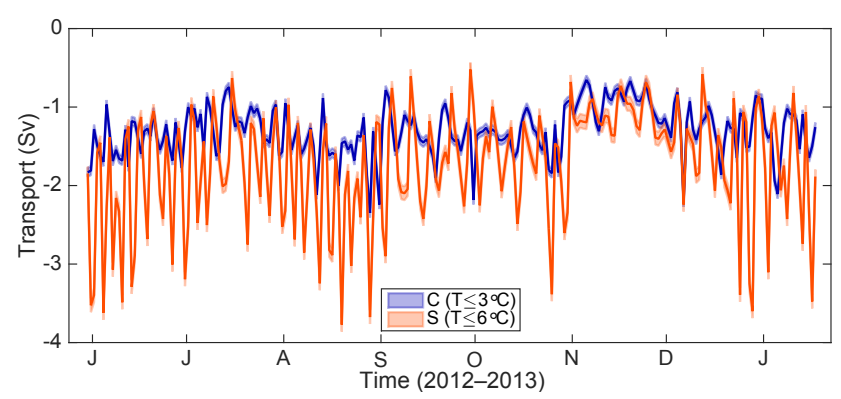

Figure 7. Time series of daily volume transport through mooring sections $\mathrm{C}$ (blue) and $\mathrm{S}$ (red). The transport at $\mathrm{C}$ includes water with temperature up to $3{ }^{\circ} \mathrm{C}$ and at $\mathrm{S}$ up to $6{ }^{\circ} \mathrm{C}$. Shading shows the standard error for each time series.

mesoscale oscillations (Darelius et al., 2015). The upper level mean current was generally directed along the plume, i.e. north-westerly, except for very weak flows in the opposite direction at the southernmost moorings in the $\mathrm{S}$ array. The mean counter-flow above 150 mab at mooring S4 was less than $2.5 \mathrm{~cm} \mathrm{~s}^{-1}$.

In the centre of the $\mathrm{C}$ array (mooring $\mathrm{C} 2$ ) daily current vectors were always directed along-plume in the bottom $200 \mathrm{~m}$. Above that, occasional reversals occurred, although rarely within $300 \mathrm{~m}$ above the seabed (Fig. 5). C1 was located near the northern edge of the plume in the channel, characterized by weaker currents and frequent reversals. 


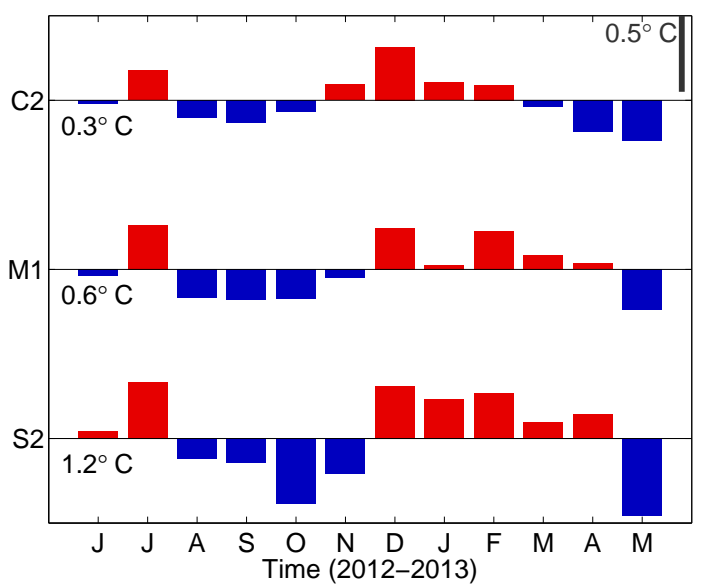

Figure 8. Time series of monthly mean temperature anomalies $\left({ }^{\circ} \mathrm{C}\right)$ at $25 \mathrm{mab}$ from three moorings along the plume path $(\mathrm{C} 2, \mathrm{M} 1$, and $\mathrm{S} 2$; see labels on the left). Each series is shown as a fluctuation about the whole deployment mean, indicated by numbers below each axis (on the left). Scale bar is given in the top right corner.

\section{Volume transport}

The volume transport of water in different temperature classes was estimated for mooring sections $\mathrm{C}$ and $\mathrm{S}$ from the gridded fields as described in Appendix B. Time series of daily transport across sections $\mathrm{C}$ and $\mathrm{S}$ are shown in Fig. 7. Considering only the period with complete vertical coverage of velocity of the cold overflow plume at all C-array moorings (see Appendix B), 30 May 2012-17 January 2013, the mean transport of overflow water at section C was $1.3 \pm 0.3 \mathrm{~Sv}$, where \pm is the standard deviation of the daily resolution time series. The standard error of the overflow transport was $0.1 \mathrm{~Sv}$, assuming independent records approximately every 4 days (the typical integral timescale and the timescale of mesoscale variability).

The overflow plume is subject to mixing and entrainment along its path, leading to changes in the water mass properties of the core (e.g. Saunders, 1990; Mauritzen et al., 2005; Fer et al., 2010). As a result, the transport of the coldest plume water $\left(<0^{\circ} \mathrm{C}\right)$ was reduced from a mean of $0.3 \pm 0.2 \mathrm{~Sv}$ at section $\mathrm{C}$ to nil at $\mathrm{S}$. The mean transport of modified overflow water at mooring section $\mathrm{S}$ was $1.7 \pm 0.7 \mathrm{~Sv}$. A wider temperature range (up to $6^{\circ} \mathrm{C}$; see Sect. 2) was considered here in order to account for the entrained water. From section $\mathrm{C}$ to section $\mathrm{S}$, the $T \leq 3^{\circ} \mathrm{C}$ part of the transport decreased by $0.5 \mathrm{~Sv}$ and the $3^{\circ} \mathrm{C}<T \leq 6^{\circ} \mathrm{C}$ class increased by $0.4 \mathrm{~Sv}$, suggesting detrainment and entrainment, respectively, in the two layers, consistent with the budget results obtained in Sect. 6.2.
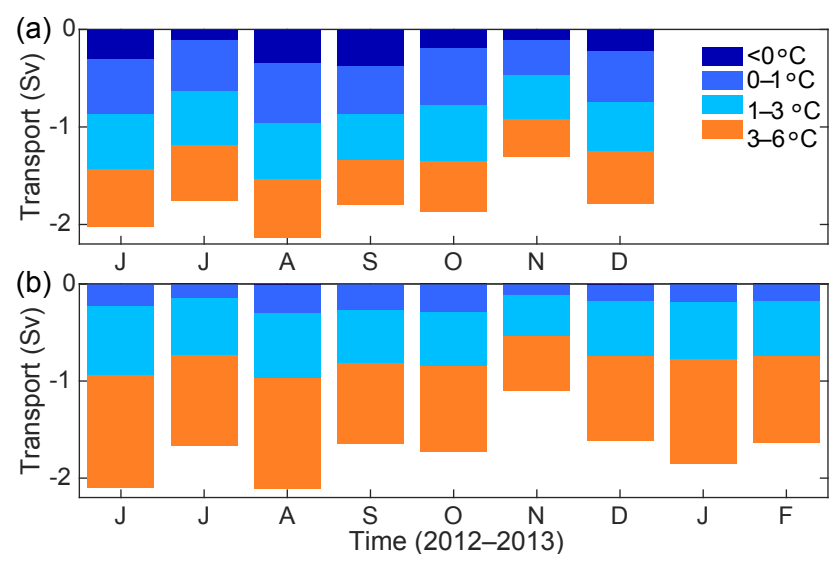

Figure 9. Monthly mean volume transport at (a) mooring array $\mathrm{C}$ and (b) array $\mathrm{S}$, per temperature class. The volume transport time series are shorter than a year because records from some current profilers (one at mooring C3 and one at mooring S3) did not cover the whole deployment; see Table A1.

\section{Temporal variability}

\subsection{Variability in different frequency bands}

Current velocities and hydrographic properties varied strongly on different timescales. Velocity power spectra (not shown) displayed a distinct peak at the semi-diurnal tidal frequency at all moorings. In addition, the $\mathrm{C}$ array of moorings showed a diurnal tidal peak. There was also elevated power spectral energy in the frequency band corresponding to mesoscale oscillations. The mesoscale spectral peak was found at frequencies corresponding to $4-8$ days at $\mathrm{C}$ and 36 days at $S$.

Time series of monthly mean temperature at 25 mab from moorings along the main plume path are shown in Fig. 8. Although this frequency band contains only a small part of the variability (about $5 \%$ for the series low-pass filtered with a 2-month cut-off compared to about $40 \%$ in the mesoscale frequency band), there is a consistent pattern between the different moorings.

The temperature in the bottom layer (Fig. 8) was lower than average during August through to October 2012 at both section $\mathrm{C}$ and further downstream. Warmer than average temperatures persisted from November 2012 to February 2013 at mooring $\mathrm{C} 2$ and through to April at M1 and S2. The maximum temperature in the bottom layer occurred in December at $\mathrm{C} 2$, and December through to February was also a warm period at M1 and S2. After the warm winter months, the temperature decreased in early spring to a minimum in May. At mooring S2 the monthly mean temperature during this coldest month was about $0.5^{\circ} \mathrm{C}$ below the long-term mean.

The variation in monthly bottom layer temperatures might be interpreted as a seasonal cycle, with generally higher temperatures in the winter months and low temperatures the rest 


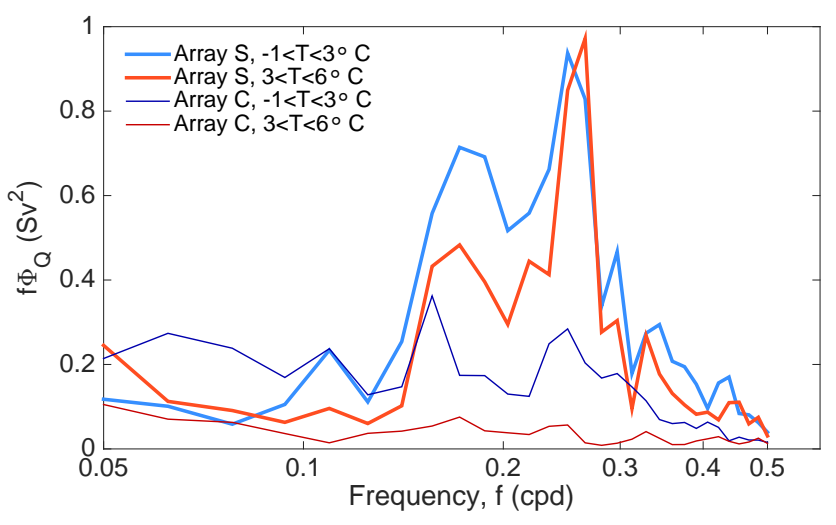

Figure 10. Variance-preserving spectra of volume transport for the upper and lower layers at mooring arrays $\mathrm{C}$ and $\mathrm{S}$, respectively.

of the year. The temperature in July, however, deviated from this pattern by being clearly above the long-term mean at both sections $\mathrm{C}$ and $\mathrm{S}$ (with maximum monthly temperatures recorded at M1 and S2), in sharp contrast to the low mean temperature of August.

Volume transport varied strongly on daily to monthly timescales (Fig. 7), but did not show a distinctive seasonal cycle (Fig. 9). The daily mean transport of water colder than $3{ }^{\circ} \mathrm{C}$ ranged between 0.7 and $2.3 \mathrm{~Sv}$ at section $\mathrm{C}$. The frequency spectra of volume transport through the arrays are shown in Fig. 10. Transport of cold water through section S varied most strongly at the timescale of mesoscale oscillations, while at section $\mathrm{C}$ low-frequency variation dominated the transport spectrum. The month-to-month variability in volume transport was largely in phase between sections $\mathrm{C}$ and S, with maxima at both sections in August and minima in November 2012 (Fig. 9).

\subsection{Mesoscale variability}

Figure 11 shows a subset of the data from the mooring array $\mathrm{S}$, showing lateral temperature changes with time along the section. This mesoscale variability is typical of the entire record. The plume takes the form of domes of cold water moving past the mooring array, as previously noted by Geyer et al. (2006) and Darelius et al. (2011). While the presence of cold water at moorings S2-S4 was associated with downslope velocities, it was associated with upslope movement at mooring S1. Velocity vectors rotated mainly clockwise at S1 and S2, and anti-clockwise at S3 and S4.

There were energetic fluctuations in volume transport in the mesoscale frequency band, particularly strong at section $\mathrm{S}$ (Fig. 10). At section $\mathrm{C}$, it was mainly the transport of overflow water $\left(T<3{ }^{\circ} \mathrm{C}\right)$ that showed higher energy at mesoscale frequencies; at section $\mathrm{S}$, there was high mesoscale variability also in the layer containing modified overflow water. The frequencies in the mesoscale band that are associated with elevated spectral energy levels corre-

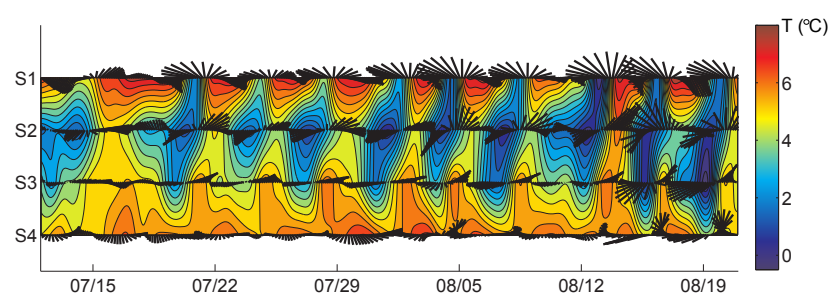

Figure 11. Hovmöller diagram of temperature $\left({ }^{\circ} \mathrm{C}\right)$ and velocity anomalies at $80 \mathrm{mab}$ across mooring section $\mathrm{S}$. Temperature scale bar on the right.

spond to periods of about 3-4 days and about 6 days, respectively. Darelius et al. (2015) have recently shown that the oscillations in the channel alternate over time between these two periods, and that time periods dominated by the higher oscillation frequency (3-4 days) coincide with larger volume transport across the sill.

The mean eddy heat flux in the mesoscale band was calculated following Voet and Quadfasel (2010). The mooring records were rotated to align with the mean current (100 mab) and band-pass filtered (2-10 days) to obtain fluctuations $v^{\prime}$ and $T^{\prime}$ in the dominant mesoscale frequency band. Finally the mean temperature flux $\overline{v^{\prime} T^{\prime}}$ was calculated at levels where both velocity and temperature data were available (Fig. 12a). The temperature fluxes were multiplied by the density $\left(\rho_{0}\right)$ and heat capacity $\left(c_{p}\right)$ to obtain heat fluxes and then integrated up to the deployment mean position of the $6{ }^{\circ} \mathrm{C}$ isotherm (numbers adjacent to moorings in Fig. 12b). The position of the isotherm was above the mooring at $\mathrm{C} 3$ and roughly at the level of the instrument at $\mathrm{S} 1$ (80 mab); no value was therefore calculated for $\mathrm{C} 3$, while the value in parentheses at $\mathrm{S} 1$ is estimated assuming a constant value of the eddy heat flux from the bottom up to 80 mab. The temperature fluxes were mostly directed upslope, i.e. to the right of the mean current, and their magnitude was of the order of $0.1 \mathrm{~K} \mathrm{~m} \mathrm{~s}^{-1}$, reaching a maximum of $0.21 \mathrm{~K} \mathrm{~m} \mathrm{~s}^{-1}$ at $\mathrm{S} 3$, 70 mab.

Downstream of the Denmark Strait overflow, eddy heat fluxes were shown to be convergent in the central part of the plume (Voet and Quadfasel, 2010), indicating that the horizontal stirring induced by the eddies there contributed significantly to the observed along-path warming of the plume. This was not in general true for the FBC region: Fig. 12b shows divergence between S4 and S3, i.e. in the central and lower parts of the plume, while the observations suggest convergence between $\mathrm{C} 2$ and $\mathrm{C} 1$ and between $\mathrm{S} 3$ and S1, i.e. for the shallow part of the plume. 


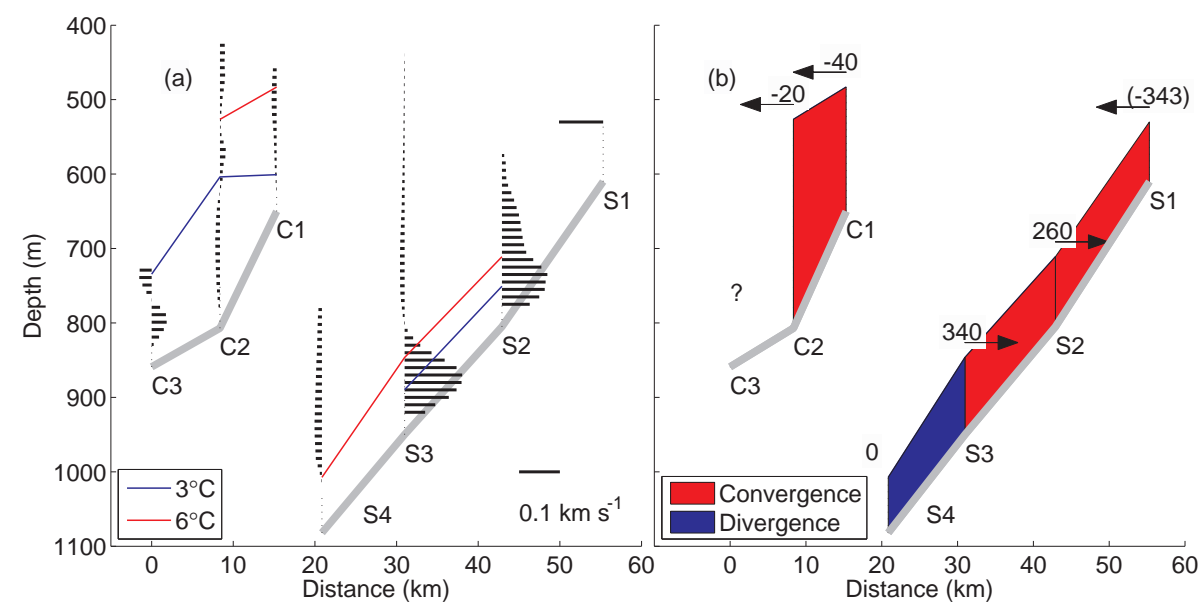

Figure 12. (a) Observed mean eddy temperature fluxes $\overline{v^{\prime} T^{\prime}}$ at mooring arrays $\mathrm{C}$ and $\mathrm{S}$ (black bar) and the deployment mean position of the $3{ }^{\circ} \mathrm{C}$ (blue line) and $6{ }^{\circ} \mathrm{C}$ (red line) isotherms. The bottom is shown in grey and the scale for the temperature fluxes is given in the lower right corner. (b) Net eddy heat flux $\left(10^{5} \mathrm{~W} \mathrm{~m}^{-1}\right)$, integrated up to the deployment mean position of the $6^{\circ} \mathrm{C}$ isotherm (red line in a). The colours indicate convergence (red) and divergence (blue) and the arrows show the direction of the flux, while the numbers above the moorings give the magnitude.
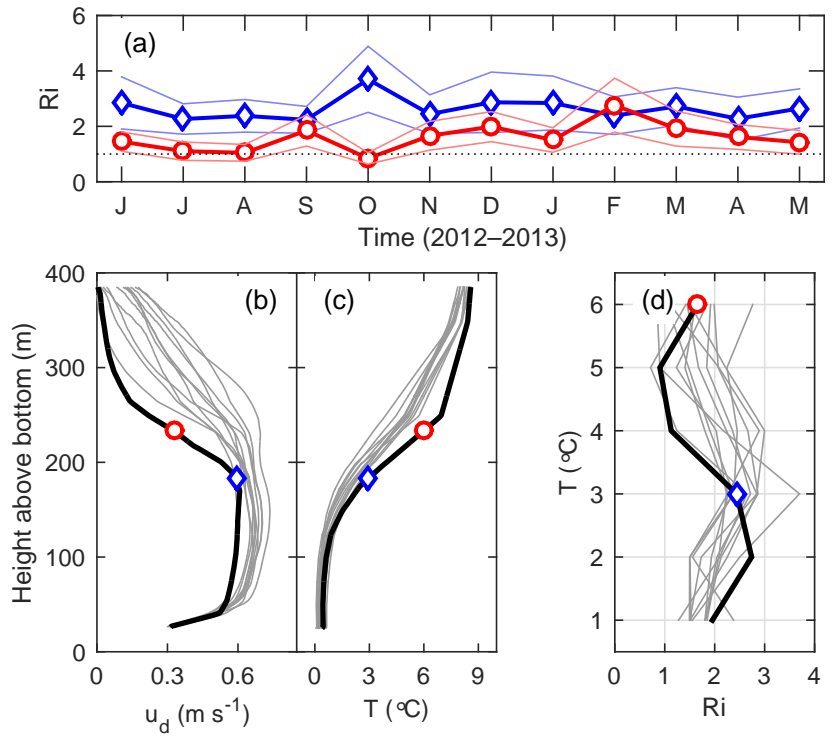

Figure 13. Monthly Richardson number, $R i$, calculations at mooring C2 in the channel. (a) Monthly averages of hourly $10 \mathrm{~m} \mathrm{Ri}$ calculated at depths centered at the $3{ }^{\circ} \mathrm{C}$ (blue, diamonds) and $6{ }^{\circ} \mathrm{C}$ (red, circles) isotherms. Envelopes are the standard error assuming every 13 th hourly sample is independent. Dashed line is $R i=1$. Profiles of (b) downstream velocity component and (c) temperature averaged in each month. The profile from May is highlighted by the bold line together with the depth of the 3 and $6{ }^{\circ} \mathrm{C}$ isotherms by the corresponding markers. (d) Monthly $10 \mathrm{~m} \mathrm{Ri}$ for unit increments of $T$. The May profile is highlighted.

\section{Diapycnal mixing}

\subsection{Stability}

The FBC overflow is a strongly sheared bottom-enhanced current characterized by energetic turbulence (Fer et al., 2010; Beaird et al., 2012). Our unique data set is used here to present the kinematic stability in different layers of the water column throughout 1 year. The gradient Richardson number, $R i$, representing the stability of stratified shear flow (Thorpe, 2007), is calculated over a $10 \mathrm{~m}$ vertical scale using the hourly and $1 \mathrm{~m}$ vertical gridded velocity and temperature profiles. Density is inferred from the temperature as described in Sect. 2. Calculations are made using data from two moorings, each sampling the core of the dense overflow plume: $\mathrm{C} 2$ at the channel, and $\mathrm{S} 2$ over the slope. For each hourly profile, the depth of the 1 to $6^{\circ} \mathrm{C}$ isotherms is identified. Vertical $10 \mathrm{~m}$ segments centered at the corresponding depths are extracted. Vertical gradients of density and of horizontal components of the velocity are obtained as the slope of the linear fit against depth. Hourly $R i$ is then calculated as $N^{2} / S^{2}$ from the vertical velocity shear squared, $S^{2}=\left(\frac{\partial u}{\partial z}\right)^{2}+\left(\frac{\partial v}{\partial z}\right)^{2}$, and the buoyancy frequency squared, $N^{2}=\left(\frac{-g}{\rho_{0}}\right)\left(\frac{\partial \sigma_{\theta}}{\partial z}\right)$. Monthly averages and standard deviations are then obtained after excluding outliers (the lowest and top $1 \%$ quantiles) in each month. Standard error is assigned using the standard deviation and degrees of freedom assuming that every 13th sample is independent (to account for the semidiurnal variability).

The FBC overflow is characterized by small values of $R i$. Very frequently, $60-80 \%$ of the time, hourly $R i$ on the slope was below 1 , and $10-30 \%$ of the time $R i$ was below $1 / 4$. 
In the channel, the core of the plume was associated with a $150 \mathrm{~m}$ thick high-velocity layer with weak shear, typically with temperatures less than $3{ }^{\circ} \mathrm{C}$. Despite the weak shear, stratification was low, and monthly averaged $R i$ varied between 2 and 4 (Fig. 13d). In the sheared interfacial layer monthly $R i$ was approximately 2 or less, and in the sheared bottom boundary layer monthly $R i$ was approximately 1 or less (the bottom boundary layer is not captured by the $1{ }^{\circ} \mathrm{C}$ class, and hence is not shown in Fig. 13d).

Microstructure measurements reported in Fer et al. (2010) show that (i) the interior core of the plume in the channel is characterized by low dissipation rates, due to weak shear and lack of turbulent kinetic energy production, and that (ii) turbulence is enhanced in a $100 \mathrm{~m}$ thick high-shear bottom layer and $100 \mathrm{~m}$ thick interfacial layer. $R i$ values derived from C2 are consistent with these measurements and imply that, in our analysis, values of $R i$ approximately 2 and less can be associated with energetic, turbulent regions of the water column.

In the channel, the $3{ }^{\circ} \mathrm{C}$ isotherm capped the low-shear core of the plume and $R i$ was typically above 2 throughout the year. The interface above, however, was turbulent at all times, and particularly in May, with average $R i<1$. In contrast to the channel profiles, the low-shear core did not exist over the slope (Fig. 14). $R i$ was typically less than 2 below the $4{ }^{\circ} \mathrm{C}$ isotherm which separated the relatively quiescent stratified layer above (the $6^{\circ} \mathrm{C}$ isotherm was characterized by average $R i>2$ throughout the year). The vertical distribution of turbulence in the overflow thus differs between the channel section and the slope section.

\subsection{Heat budget estimation of entrainment/detrainment}

From each mooring array (C and S), daily averages of volume transport, mean temperature, layer thickness, and crosssectional area binned in temperature classes were used to construct a volume-averaged heat budget for the time period spanned by both arrays (30 May 2012-17 January 2013). The budget method assumes a steady state and follows Hogg et al. (1982) and Whitehead and Worthington (1982). Two layers were considered: one delineated by the seabed and the $3{ }^{\circ} \mathrm{C}$ isotherm and the other one above it, bounded by the 3 and $6^{\circ} \mathrm{C}$ isotherms. Mooring array $\mathrm{C}$ defines the inflow section, while array $\mathrm{S}$ is the outflow section of the control volume (see Fig. 15).

In steady state, the volume budget can be written as

$$
\begin{aligned}
& Q_{\mathrm{Bi}}=Q_{3}+Q_{\mathrm{Bo}}+Q_{\mathrm{EK}}, \\
& Q_{\mathrm{Ui}}+Q_{3}=Q_{6}+Q_{\mathrm{Uo}},
\end{aligned}
$$

where indices B and $\mathrm{U}$ refer to the bottom and upper layers, respectively; i refers to inflow (through array C) and o refers to outflow (array $\mathrm{S}$ ), and all quantities are time averaged over a suitable time window (defined below). The inflow and outflow are first integrated vertically over the layer and then
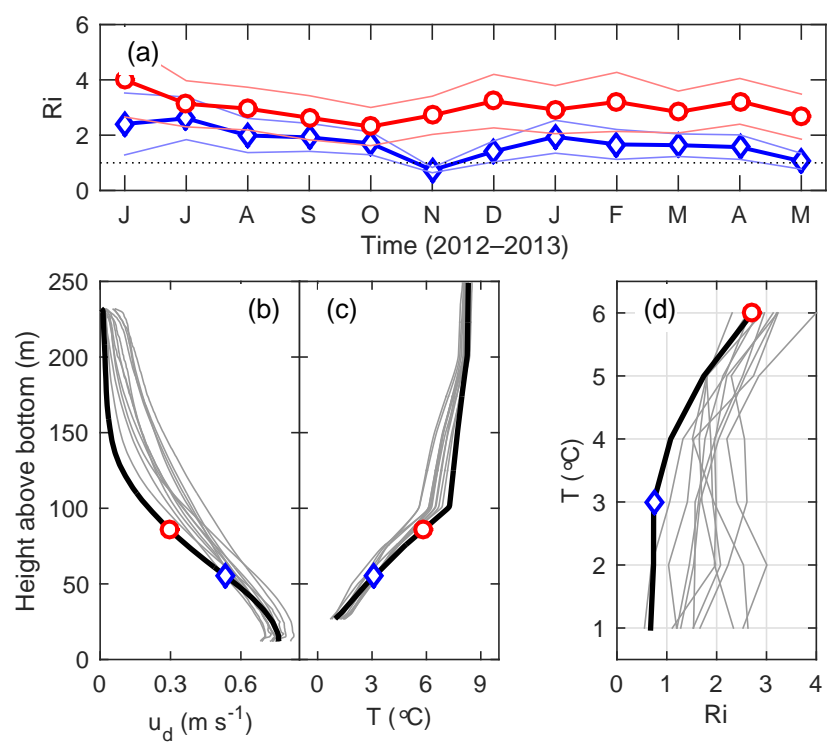

Figure 14. Same as Fig. 13 but for mooring S2, on the slope.

horizontally across the section before time averaging. Spatial and temporal averaging operators are omitted from the equations for simplicity. $Q_{\mathrm{EK}}$ is the bottom Ekman transport, and $Q_{3}$ and $Q_{6}$ are the average vertical transports (positive upward) across the 3 and $6^{\circ} \mathrm{C}$ isotherms, respectively.

The heat budget can then be expressed, using the timeaveraged quantities, as

$$
\begin{aligned}
& Q_{\mathrm{Bi}} T_{\mathrm{Bi}}=F_{\mathrm{H} 3}+3 Q_{3}+Q_{\mathrm{Bo}} T_{\mathrm{Bo}} \text { and } \\
& Q_{\mathrm{Ui}} T_{\mathrm{Ui}}+F_{\mathrm{H} 3}+3 Q_{3}=F_{\mathrm{H} 6}+6 Q_{6}+Q_{\mathrm{Uo}} T_{\mathrm{Uo}} .
\end{aligned}
$$

In this section we use kinematic heat flux, that is, the temperature flux $v T$. The diffusive heat flux, averaged over volume and time, is approximated as $F_{\mathrm{H}}=-K_{z}(\mathrm{~d} T / \mathrm{d} z) L W$, where $K_{z}$ is the average vertical diffusivity, $L$ is the horizontal along-path separation between the arrays, $W$ is the average plume width defined by the given isotherm, and $\mathrm{d} T / \mathrm{d} z$ is the average vertical temperature gradient. This approximation is typically invoked in the budget calculations, and is valid if the local values of diffusivity and the vertical temperature gradient are not correlated. Our resulting estimates of average vertical diffusivity should thus be interpreted with this caveat in mind. $L$ was chosen as $60 \mathrm{~km}$. In the calculations we used transport weighted temperature for the layers (see e.g. Duncan et al., 2003). For each layer, $\mathrm{d} T / \mathrm{d} z$ is calculated as the difference between (transport weighted) average temperature divided by the difference in average thickness in each layer. We assumed that the upper layer underlies a $50 \mathrm{~m}$ thick top layer at a temperature of $7.5^{\circ} \mathrm{C}$.

The budget was calculated using averages over 30-day long segments of the daily time series which are moved by 1 day throughout the record (that is, 1-day moving 30-day width windows). The 30-day window sufficiently averages over the 3-5-day mesoscale variability. While the steady- 

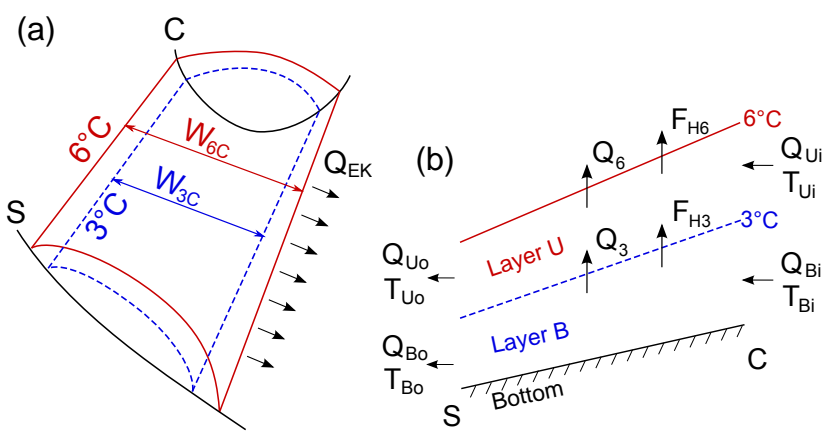

Figure 15. A schematic view of the overflow plume between sections $\mathrm{C}$ and $\mathrm{S}$, demonstrating the components of the heat budget. The $3{ }^{\circ} \mathrm{C}$ isotherm marks the upper limit of the bottom (B) layer, and the $6^{\circ} \mathrm{C}$ isotherm the upper limit of the upper (U) layer.

state assumption is questionable, the variability in section volume transports is mainly contained in timescales less than 10 days (see Fig. 10 for the variance-preserving transport spectra). Budget calculations using time-average windows from 5 days to 3 months with 5-day increments (not shown) confirm that the results are not sensitive to the choice of the 30 -day window after approximately $15-25$ days. We thus expect the budget calculations to be fairly representative of the steady state, and to yield a more accurate estimate of entrainment rates compared to analysis of snapshots of hydrography and currents from single cruises. Because the mesoscale variability is averaged, the eddy fluxes discussed in Sect. 5.2 are not included in the formulation of the heat budget. The Ekman transport is $Q_{\mathrm{EK}}=\left(C_{\mathrm{D}} V^{2} / f\right) L$, where the drag coefficient $C_{\mathrm{D}}=3.7 \times 10^{-3}$ is from direct turbulence measurements of the FBC overflow (Fer et al., 2010), and $V$ is the spatial mean flow of the plume at the given time. For $V$ we use an average over both the bottom and upper layers and over both arrays (average transport divided by average crosssectional area). The results are not sensitive to using only the bottom layer average. The long-term mean value of $Q_{\mathrm{EK}}$ estimated in this way was $0.3 \mathrm{~Sv}$. $Q_{\mathrm{EK}}$ does not contribute to the heat budget because the near-bottom temperature is approximately $0^{\circ} \mathrm{C}$ and thus equal to the reference temperature.

The magnitude of the different terms in the budget can be compared to justify the exclusion of lateral eddy fluxes and the heat flux associated with $Q_{\mathrm{EK}}$. The average advective heat fluxes, $Q T$, and diffusive heat fluxes, $F_{\mathrm{H}}$, are of the order $1 \mathrm{~Sv}^{\circ} \mathrm{C}$ with 1 order of magnitude smaller standard deviation. $Q T$ in the upper layer is 2 (section $\mathrm{C}$ ) to 4 times (section $\mathrm{S}$ ) larger than the values in the bottom layer (approximately $1.3 \mathrm{~Sv}^{\circ} \mathrm{C}$ at both sections), and the diffusive fluxes are approximately $0.7 \mathrm{~Sv}^{\circ} \mathrm{C}$ downward, across each layer. In comparison, the bottom Ekman heat flux averaged over both sections is $-0.02 \mathrm{~Sv}^{\circ} \mathrm{C}$ (hence negligible). Using the magnitudes given in Fig. 12, the net average eddy heat flux integrated to the $6^{\circ} \mathrm{C}$ isotherm, averaged over both sections, is of the order $100 \times 10^{5} \mathrm{~W} \mathrm{~m}^{-1}$, or integrated over $L=60 \mathrm{~km}$
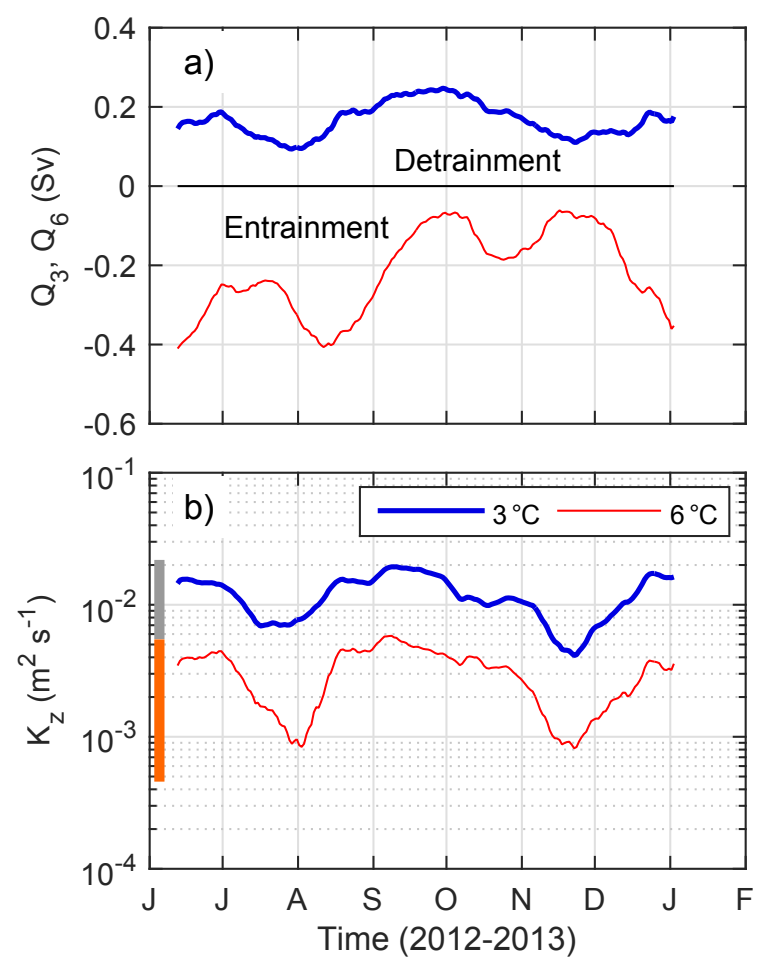

Figure 16. Time series of (a) detrainment and (b) vertical diffusivity inferred from monthly heat budgets in daily moving windows. In (a) positive values indicate detrainment. Budgets are obtained between arrays $\mathrm{C}$ and $\mathrm{S}$ and between the bottom and the $3{ }^{\circ} \mathrm{C}$ isotherm (blue) and between the 3 and $6^{\circ} \mathrm{C}$ isotherms (red); cf. Fig. 15. Vertical bars in (b) are the ranges of vertical diffusivity in the corresponding layers observed in June 2010 and 2012 using microstructure profilers (Fer et al., 2010, 2014).

(and converting to temperature flux) is $0.15 \mathrm{~Sv}{ }^{\circ} \mathrm{C}$. The uncertainty is not quantified and is possibly large. Nevertheless, the eddy heat flux term is 1 order of magnitude less than the advective heat fluxes and approximately $20 \%$ of the diffusive flux. The contribution of the eddy heat flux to the heat budget is probably much less since the rotational component of the eddy flux is not removed (see Sect. 7).

The heat budget was used to estimate rates of entrainment and detrainment (Fig. 16a). Throughout the whole period there was always detrainment from the bottom layer and entrainment into the upper layer: $Q_{3}$ was positive throughout, with a long-term mean of $0.2 \mathrm{~Sv}$, and $Q_{6}$ negative, with a mean of $-0.2 \mathrm{~Sv}$. Entrainment in the upper layer peaked in June and August, and was at minimum levels in October and December. December was also a time of minimum detrainment in the bottom layer.

The mean vertical diffusivities inferred from the heat budget were $(120 \pm 43) \times 10^{-4}$ for the bottom layer and $(30 \pm$ 15) $\times 10^{-4} \mathrm{~m}^{2} \mathrm{~s}^{-1}$ for the upper layer. The sensitivity of these results to the choices of various parameters in the heat budget was tested. Increasing the value of $L$ chosen to represent the distance between the mooring arrays by $10 \%$ reduced $K_{z}$ 
in each layer by $8-9 \%$. An increase in assumed thickness of the top layer overlying layer $\mathrm{U}$ from 50 to $100 \mathrm{~m}$ led to an increase in mean $K_{z \mathrm{U}}$ by $14 \%$, while keeping the thickness at $50 \mathrm{~m}$, and instead increasing the temperature by $1{ }^{\circ} \mathrm{C}$ reduced the mean $K_{z \mathrm{U}}$ by $20 \%$. Determining $\mathrm{d} T / \mathrm{d} z$ from temperature and thickness values at only one mooring array, instead of averaging over both, led to a $13 \%$ increase (using values from C) or decrease (values from $\mathrm{S}$ ) in $K_{z \mathrm{U}}$. The sensitivities are thus less than the error bounds (1 standard deviation) given for $K_{z}$.

\section{Discussion}

\subsection{General overflow characteristics}

The topography, with the narrow channel opening onto the Iceland-Faroe slope, affects the anatomy and mixing of the FBC overflow. The overflow plume became markedly thinner between mooring sections $\mathrm{C}$ and $\mathrm{S}$. Not only the average temperature but also the shape of both the velocity and temperature profiles changed, so that the thickness of the wellmixed bottom layer decreased (see Fig. 3). The reduction in height reflects the spreading and thinning of the plume on the open slope after escaping the topographic constraint of the channel. The thinning of the plume with distance downstream was accompanied by increased velocities (see Figs. 5 and 6), as previously observed by e.g. Mauritzen et al. (2005) and Duncan et al. (2003).

Inside the thick core of the plume in the channel, there was a $150 \mathrm{~m}$ thick weak shear layer. As shown by Fer et al. (2010), the flow in this layer was relatively stable (higher $R i$ ) compared to the more turbulent layers above and below it (in the interface and towards the bottom, respectively). The thinner and faster plume at section S, however, had no such quiescent layer. The low values of $R i$ (average $<1$ throughout the year) below about $150 \mathrm{mab}$ at $\mathrm{S}$ and for a layer centred at about 300 mab at $\mathrm{C}$ demonstrate the high potential for turbulence generation due to the strongly sheared flow, despite the strong stratification. Similar results from earlier process studies (Borenäs and Lundberg, 1988; Saunders, 1990; Fogelqvist et al., 2003; Fer et al., 2010) are thus corroborated by our longer-term data set.

At the mooring section in the channel, the plume was faster, thinner, and colder toward the southern (Faroe Bank) side of the section. This is in agreement with the observation by Hansen and Østerhus (2007) that the core velocity decreases and the thickness of the plume increases toward the right (looking downstream), and is a typical structure for a gravity current confined to a channel in a rotating system (cf. Guo et al., 2014). The stronger thermal stratification found on the southern side is an example of the "isotherm pinching" observed on the southern side of the channel (e.g. Borenäs et al., 2001).

\subsection{Downstream transport evolution and flow bifurcation}

In classical descriptions of dense overflows, the volume transport of an overflow is assumed to increase gradually - or abruptly at mixing hotspots - due to entrainment of the overlying waters (Price and O’Neil Baringer, 1994; Legg, 2012). For the FBC overflow, intensive mixing has been observed in locations just west of the channel exit (Duncan et al., 2003; Mauritzen et al., 2005; Fer et al., 2010; Beaird et al., 2012). The mixing results in large changes in water mass properties; south of Iceland the boundary current contains only about half overflow water and half admixed upper layer water (Fogelqvist et al., 2003). If there was no detrainment (as suggested by Mauritzen et al., 2005), a doubling of the overflow volume transport might thus be expected (Hansen and Østerhus, 2007). On the basin scale, the total transport of Iceland Scotland Overflow Water increases with distance along its path through the North Atlantic by on average $1.8 \mathrm{~Sv}$ over $1000 \mathrm{~km}$ (Kanzow and Zenk, 2014) which would correspond to $0.1 \mathrm{~Sv}$ between sections C and S. Mauritzen et al. (2005) observed an increase in dense water transport (although the densest classes vanished) between CTD sections progressing downstream in the FBC outflow region. A recent model study of the FBC overflow by Guo et al. (2014) showed a downstream increase in overflow volume transport (for temperatures $\leq 6{ }^{\circ} \mathrm{C}$ ) of about $0.6 \mathrm{~Sv}$ over $90 \mathrm{~km}$.

Our data set, however, shows no corresponding increase from mooring array $\mathrm{C}$ to array $\mathrm{S}$. To explore this surprising result, we must first ask ourselves whether our measurements covered the entire plume at both sections.

At array $\mathrm{C}$, overflow water on average occupied the lower $120 \mathrm{~m}$ at the southernmost mooring (see Sect. 3). The southern boundary of the plume must thus be south of the mooring section, but because the flow here is constrained by topography, the plume cannot extend far to the south. Our horizontal extrapolation adequately compensates for the edges of the plume; our mean volume transport estimate for water colder than $3{ }^{\circ} \mathrm{C}$ of $1.3 \pm 0.3 \mathrm{~Sv}$ is within the range of earlier estimates for the FBC overflow varying between 1.1 and $2.1 \mathrm{~Sv}$ (van Aken and Becker, 1996; Hansen and Østerhus, 2000; Kanzow and Zenk, 2014). The estimated volume transport at array $\mathrm{C}$ is about two-thirds of the kinematic overflow estimate at the sill (Darelius et al., 2015, and Appendix B).

The S section was not located in the channel, but on the open slope. The question of how that mooring array was positioned with respect to the plume path is therefore important. First, we consider the statistics of the observed temperature and velocity at the moorings at section $\mathrm{S}$. There was a clear presence of overflow water throughout the year at the two moorings S2 and S3 in the centre of the array, while at the two moorings at the edges, cold plume waters were only occasionally present. At the northernmost mooring, S1, overflow waters $\left(T \leq 3{ }^{\circ} \mathrm{C}\right)$ were found at $80 \mathrm{mab}$ (the only measurement level here) less than $10 \%$ of the time and modified 


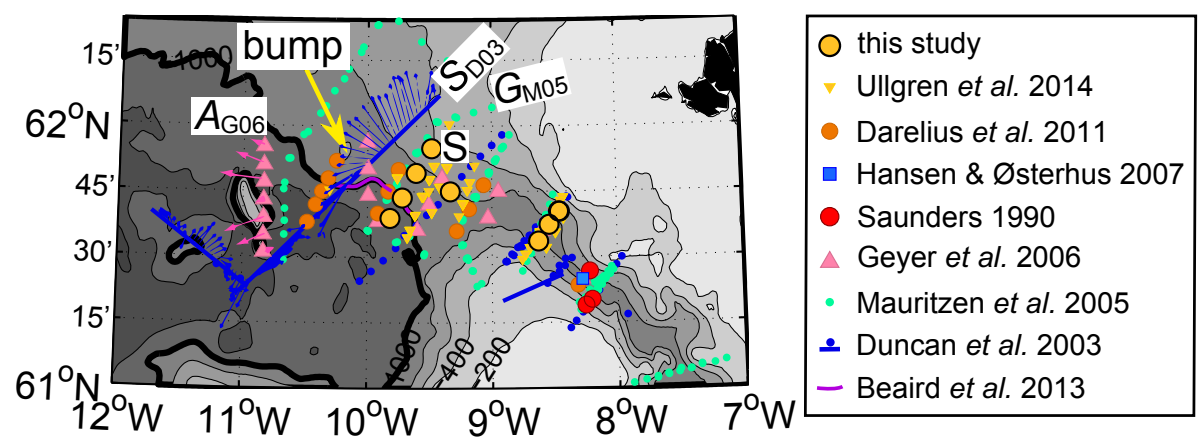

Figure 17. Map showing the positions of the moorings in this study together with the mooring positions of Darelius et al. (2011), Hansen and Østerhus (2007), Saunders (1990), and Geyer et al. (2006). Also shown are CTD station positions from Ullgren et al. (2014) as well as station locations from Mauritzen et al. (2005), and hydrographic sections with CTD/LADCP and deep towed vehicle from Duncan et al. (2003). Shaded bathymetric contours are plotted every $200 \mathrm{~m}$; the $1000 \mathrm{~m}$ contour is bold. Our mooring array S, Geyer's (2006) mooring array A $\left(\mathrm{A}_{\mathrm{G} 06}\right)$, Duncan's section S ( $\left.\mathrm{S}_{\mathrm{D} 03}\right)$, and Mauritzen's section $\mathrm{G}\left(\mathrm{G}_{\mathrm{M} 05}\right)$ are labelled. Current arrows from $\mathrm{S}_{\mathrm{D} 03}$ and $\mathrm{A}_{\mathrm{G} 06}$ are shown schematically - not to scale. The topographic bump associated with bifurcation of the flow is marked by a yellow arrow, and a purple line roughly corresponds to the portion of the $1000 \mathrm{~m}$ isobath where the deeper edge of the plume was found to be deeper than the depth range of Seagliders in Beaird et al. (2013, their Fig. 6).

overflow waters $\left(T \leq 6{ }^{\circ} \mathrm{C}\right)$ less than $35 \%$ of the time. At the southernmost mooring, $\mathrm{S} 4$, the corresponding percentages at the same height above seabed were less than $2 \%$ for $T \leq 3{ }^{\circ} \mathrm{C}$ and about $36 \%$ for $\leq 6{ }^{\circ} \mathrm{C}$. At both moorings, the lowest temperatures were correlated with stronger along-stream velocity, a clear indication of plume presence on such occasions. Cold water was present at these moorings only during periods with energetic oscillations (Darelius et al., 2015), suggesting that it is brought here by the eddy motion. Most of the time, however, the overflow was found in the centre of the array while absent at the outer moorings (i.e. the boundaries of the plume were found within the mooring array).

There are no channel walls on section $\mathrm{S}$ to contain the overflow; however, the shallow topography north of array S likely prevents large excursions of the plume to the north (upslope). There is no evidence in the literature of a plume path north of mooring S1. The mean current of the overflow mainly follows isobaths (Geyer et al., 2006), until it begins to descend under the influence of friction (Seim et al., 2010). Are there then downslope excursions that make the overflow pass south of section S? The occurrence of cold water at mooring S4 was rare, and the long-term average velocity there was approximately 0 (see Figs. 1 and 3). Our observations thus do not show any evidence of significant overflow at (or beyond) the southern end of array S. However, we cannot rule out the possibility that a fraction of the overflow plume was not captured by our array, especially during periods of strong mesoscale activity.

A second important issue to consider is the bifurcation of the flow. The overflow is known to split into two branches. The shallower branch flows westward, approximately following the isobaths along the Atlantic flank of the IcelandFaroe Ridge, and the deeper branch turns southwestward and descends more directly into the southern Iceland Basin
(Beaird et al., 2013; Hansen and Østerhus, 2000). The splitting appears to occur between the secondary sill at about $9^{\circ} \mathrm{W}$ and a topographic "bump" or plateau further downstream (Mauritzen et al., 2005; Beaird et al., 2012, 2013). In designing our mooring array $\mathrm{S}$, we chose a location to the east (i.e. upstream relative to the overflow) of the suspected bifurcation location to ensure as complete a lateral coverage of the plume as possible. Does the weak flow at mooring S4 indicate that the bifurcation occurred upstream of array $S$ and that S4 thus was located between the branches? If, for example, there is more substantial detrainment due to bottom Ekman transport than we have assumed (estimated long-term mean $Q_{\mathrm{EK}}=0.3 \mathrm{~Sv}$ ), might this detrained water form a separate branch that turns southward before reaching array S? These questions can only be answered speculatively based on our present measurements. We turn to the literature to find indications of where the bifurcation is most likely to occur.

Repeat hydrographic sections from the multi-vessel Overflow survey in June 1960 (Lee, 1967; Tait, 1967) showed the cold core of the overflow centred at about $800 \mathrm{~m}$ depth, $10^{\circ} \mathrm{W}$ (station $\mathrm{F} 1$ at $61^{\circ} 54^{\prime} \mathrm{N}, 10^{\circ} 06^{\prime} \mathrm{W}$ - very close to the "bump" centred at $61^{\circ} 54^{\prime} \mathrm{N}, 10^{\circ} 07^{\prime} \mathrm{W}$; cf. Beaird et al., 2012). However, maps of overflow thickness and percentage overflow water based on the same survey data suggested a bifurcation of the overflow beginning already upstream of this (see Figs. 3:108 and 3:109 in Hermann, 1967). Synthesizing the observations of the 1960 survey, the Overflow 1973 experiment (Müller et al., 1979), and some evidence from geological studies, Hansen and Østerhus (2000) suggested an "alternative path" (see their Figs. 43 and 49) for the overflow, turning southwestward and descending more directly and deeper in the (south-eastern) Iceland Basin. In a more recent study, the bottom temperature distribution measured by gliders indicated a branch of the overflow descending deeper 
than $1000 \mathrm{~m}$, somewhere in the region close to our mooring section S (purple line in Fig. 17; cf. Beaird et al., 2013). This branch could not be resolved because of the $1000 \mathrm{~m}$ depth rating of the gliders.

During a survey conducted in June 2000, Mauritzen et al. (2005) found dense waters and high velocities as deep as between the 1000 and $1200 \mathrm{~m}$ isobaths at their section G, only about $5 \mathrm{~km}$ downstream of our array S (Fig. 17; for comparison, mooring S4 was located at a depth of $1082 \mathrm{~m}$ ). The authors remark, however, that the occupation of section $G$ shown in the paper (their Figs. 23 and 24) took place after a storm when the overflow transport doubled. A better temporal averaging is provided from the survey in June 2012 reported in Ullgren et al. (2014). In a section repeated five times over the course of $70 \mathrm{~h}$, located about $10 \mathrm{~km}$ upstream of our mooring array $\mathrm{S}$, the high-velocity core of the overflow was mostly centered close to, or shallower than, the $1000 \mathrm{~m}$ isobath, with reduced flow at the outer two stations (Ullgren et al., 2014).

Mauritzen et al. (2005) mention that a division into two branches at about $900 \mathrm{~m}$ depth is indicated at their westernmost section, $\mathrm{H}$, located about $50 \mathrm{~km}$ downstream of our array $\mathrm{S}$. (Section $\mathrm{H}$ is marked by green dots but not labelled in Fig. 17; it is the section the lower part of which is parallel and close to Geyer's section A.) They suggest that the bifurcation occurs somewhere between their sections $\mathrm{G}$ and $\mathrm{H}$, where the flow decelerates and is "separated by a plateau in the topography" (Mauritzen et al., 2005, p. 910). Most likely this flow separation is thus caused by the same topographic feature that Beaird et al. (2013) refer to as the "bump" (see Fig. 17).

Mean current velocity vectors from July to November 1999 presented by Geyer et al. (2006) show a split into two branches at about $11^{\circ} \mathrm{W}$ (their Fig. 3), also west of our mooring section S (see Fig. 17). Note that this is a split of a deeper flow around a different topographic feature, southwest of the bump of Beaird et al. (2013). The location of the knoll dividing the flow in the paper by Geyer et al. (2006) fits with the observation by Swift (1984) that data sets from the Overflow 1960 and 1973 expeditions (Tait, 1967; Müller et al., 1979) both show a "similar three-way splitting of the overflow tongue at about $61^{\circ} 45^{\prime} \mathrm{N}$ and $11^{\circ} \mathrm{W}$ ".

The complex topography that varies strongly on small scales is a major factor controlling overflow pathways in simulations (Chang et al., 2009). Tracer-weighted average plume paths from model experiments by Seim et al. (2010) and Riemenschneider and Legg (2007) generally turn more southward and descend below the $1000 \mathrm{~m}$ isobath close to (but typically west of) the location of array S.

Further evidence of the overflow splitting into a deeper branch and a shallower branch in the region just west of array $S$ is found in velocities measured at 64 mab by a deep towed vehicle (Fig. 7 in Duncan et al., 2003). The current below about $900 \mathrm{~m}$ veered downslope at a section located about $20 \mathrm{~km}$ downstream of array S (Fig. 17). Two out of the three bottom-following float trajectories shown by Prater and Rossby (2005) followed roughly along the $1000 \mathrm{~m}$ isobath until at least $11^{\circ} \mathrm{W}$, while one track descended earlier (closer to mooring array S). It should be noted that for the latter, as well as for one of the other floats, the positions along this part of the track were only estimates not directly determined by sound ranging.

In summary, mooring array $\mathrm{S}$ is located in the general region where the FBC overflow divides into branches, and we cannot rule out the possibility that a branch has been diverted before reaching S. A detailed comparison with the literature, however, suggests that the majority of earlier works place the split a short distance downstream of array S. The bifurcation (or one bifurcation) appears most likely to be caused by the topographic bump centred at about $61^{\circ} 54^{\prime} \mathrm{N}, 10^{\circ} 7^{\prime} \mathrm{W}$, approximately $30 \mathrm{~km}$ downstream of array $\mathrm{S}$.

Assuming on this basis that mooring array $\mathrm{S}$ did not miss a substantial branch of the overflow, our observations indicate that the simplified view of along-path volume increase may not be accurate for the FBC overflow. As the plume proceeds into the stratified ambient water, there is substantial detrainment from the deeper layer, of comparable magnitude to the entrainment into the interfacial layer. Although the maximum plume velocity was measured at the downstream array, the volume transport of plume water with $T \leq 3^{\circ} \mathrm{C}$ decreased to $0.8 \pm 0.4 \mathrm{~Sv}$ at section $\mathrm{S}$. As expected, the volume transport of the coldest waters disappeared $\left(T \leq 0^{\circ} \mathrm{C}\right)$ or was reduced $\left(0^{\circ} \mathrm{C}<T \leq 1^{\circ} \mathrm{C}\right)$ between section $\mathrm{C}$ and section $\mathrm{S}$. A reduction in the low-temperature classes of FBC overflow transport within the first few hundred kilometres downstream of the sill was shown by Duncan et al. (2003), while Beaird et al. (2013) found a downstream decrease in transport regardless of water class definitions used. Similarly, Fer et al. (2010) found no increase in volume transport in the bottom cold layer despite dilution typically indicating entrainment. They suggested that the dilution might instead be caused by warmer interface layer water being supplied to the bottom layer by the transverse circulation, replacing bottom water lost through bottom Ekman drainage. Throughout our yearlong measurements, there was persistent detrainment from the bottom layer and entrainment into the interfacial layer; the decrease in cold water transport between sections $\mathrm{C}$ and $\mathrm{S}$ was compensated for by a roughly equal increase in transport in the intermediate temperature range $3^{\circ} \mathrm{C}<T \leq 6^{\circ} \mathrm{C}$. The total mean transport of overflow and modified overflow together thus did not change between the channel and the slope sections. Simple estimates of the contribution of the FBC overflow to the global thermohaline circulation assume doubling of the volume transport due to entrainment. Our observations suggest that, despite substantial entrainment, volume transport does not increase significantly because of detrainment. In that case, the FBC overflow could be less important for the production of North Atlantic Deep Water and for assessing changes in the global thermohaline circulation 
than is usually assumed (Hansen et al., 2001; Dickson et al., 2002).

\subsection{Variability and mixing}

No clear seasonal cycle was detected in the volume transport of the FBC overflow, but there was variability at monthly timescales. Transport peaked at both sections in June and August 2012, coinciding with maximum entrainment into the upper layer. Minimum entrainment in the upper layer occurred in October 2012, a month that was marked by minimum bottom layer temperatures both at section $\mathrm{S}$ and the mid-mooring M1. Saunders (1990) found no seasonality of plume thickness, temperature, or velocity in year-long measurements, but Hansen and Østerhus (2007) showed a seasonal variation of kinematic overflow at the sill of about $10 \%$ of the mean over a 10-year period. The relatively low amplitude of the seasonal cycle compared to shorter-term variations means it only becomes apparent in data sets covering several years. The seasonal variability in the outflow has been linked to seasonality in the barotropic northward flow of Atlantic Water in the Faroe-Shetland Channel (Lake and Lundberg, 2006). Darelius et al. (2015) showed that variability in volume flux on shorter timescales is linked to the local barotropic forcing.

Mean diffusivities inferred from the two-layer heat budget constructed for the overflow were $(30 \pm 15) \times 10^{-4} \mathrm{~m}^{2} \mathrm{~s}^{-1}$ for the upper layer and $(120 \pm 43) \times 10^{-4} \mathrm{~m}^{2} \mathrm{~s}^{-1}$ for the bottom layer, within the range of values observed during research cruises in 2010 and 2012 (Fer et al., 2010, 2014). Earlier estimates have ranged between 50 and $500 \times 10^{-4} \mathrm{~m}^{2} \mathrm{~s}^{-1}$ (cf. Saunders, 1990; Duncan et al., 2003); however, they suffer from not resolving the mesoscale variability. The vertical diffusivity in both layers shows a factor of 5 increase in late August and late December. These changes coincide with periods of high eddy kinetic energy reported in Darelius et al. (2015), suggesting that the energetic mixing is associated with mesoscale variability.

Guo et al. (2014) propose that the mesoscale variability in the FBC is caused by baroclinic instability of the plume. In their model experiment, the baroclinic instability and resulting variability are energized downstream of the sill, and high baroclinic conversion rates occur 40-60 km downstream of the sill. This is consistent with our Fig. 10, which shows more energetic mesoscale transport fluctuations at section $\mathrm{S}$ than at $\mathrm{C}$.

Eddy heat fluxes were divergent in the central and deep part of the plume and convergent between the northernmost (upper) moorings on each section, indicating that the effect of eddy heat transports is a net cooling of the deep part of the plume and a net warming of the shallower part. The observed temperature fluxes of the order of $0.1 \mathrm{~K} \mathrm{~m} \mathrm{~s}^{-1}$ were about 10 times larger than the values reported by Voet and Quadfasel (2010) from the region downstream of the Denmark Strait overflow and in agreement with values reported by Darelius et al. (2011) and the modelled values by Guo et al. (2014). Since density is largely determined by temperature in the FBC, the upslope temperature flux is equivalent to an upslope buoyancy flux, i.e. a release of potential energy. This is consistent with eddy generation due to baroclinic instability, shown by Guo et al. (2014) to be the mechanism at play in the FBC. The observed heat or buoyancy fluxes are the sum of a (dynamically unimportant) rotational component and a residual, divergent component which is the one responsible for the energy conversion (Marshall and Shutts, 1981). While our data set does not allow us to separate the two components, we note that, in this region, the total flux field and the divergent flux field are relatively similar in the model study by Guo et al. (2014).

\section{Conclusions}

One-year long moored measurements of currents and hydrographic properties in the overflow region of the Faroe Bank Channel (FBC) have provided time series of plume characteristics, volume transport, and vertical mixing from two cross sections along the path of the dense overflow plume. One section was located in the narrow channel (C) that geographically constrains the overflow. The other section was on the slope (S) after the channel topography opens up but before the bumps or knolls at $10^{\circ} 07^{\prime} \mathrm{W}$ and $11^{\circ} \mathrm{W}$ where the plume is most likely to split into multiple branches. The anatomy of the plume, the variability of velocity and hydrographic properties in space and time, as well as the mixing characteristics are found to differ between the two sections. The volume transport through the slope section was dominated by mesoscale variability, while transport through the channel section was less strongly influenced by the 3-5-day oscillation. Inferred lateral heat (equivalent to buoyancy) fluxes and the energization of the mesoscale variability with downstream distance from the sill are consistent with earlier findings supporting baroclinic instability of the overflow plume. The long-term mean overflow transport towards the Iceland Basin of waters colder than $3^{\circ} \mathrm{C}$ was $1.3 \pm 0.3 \mathrm{~Sv}$ at section C. The transport at section $\mathrm{S}$, consisting of modified overflow water with temperatures up to $6^{\circ} \mathrm{C}$, was $1.7 \pm 0.7 \mathrm{~Sv}$. In the channel, turbulence was likely to be generated near the bottom and at the interface capping the relatively quiescent thick plume core. At section S, in contrast, the whole plume layer - here thinner but faster - was marked by low $R i$ values throughout the year. Based on a two-layer heat budget constructed for the overflow, mean diffusivities across the top of the bottom mixed layer and across the interfacial layer are $(30 \pm 15) \times 10^{-4}$ and $(120 \pm 43) \times 10^{-4} \mathrm{~m}^{2} \mathrm{~s}^{-1}$, respectively. The present study provides a more accurate observational-based estimate of the volume transport, entrainment, and eddy diffusivities associated with the overflow plume because the data set resolves the temporal variability and typically covers the entire lateral and vertical extent of 
the plume. The contribution of the FBC overflow (and the dense Greenland-Scotland Ridge overflows in general) to the North Atlantic Deep Water is sometimes estimated based on an assumed doubling of the volume transport due to entrainment. Our data, although limited to a region close to the overflow site, suggest that this description may not be accurate. As the plume proceeds into the stratified ambient water, there is substantial detrainment from the deeper layer, of comparable magnitude to the entrainment into the interfacial layer. We cannot draw a firm conclusion, however, as we cannot rule out the possibility that our mooring array $\mathrm{S}$ missed a denser southern branch.

Most earlier studies indicate that the overflow does not split into branches before reaching array S. Provided that this is true, a simplified view of along-path entrainment of a gravity current may not be valid for the FBC overflow. A more accurate quantification of the $\mathrm{FBC}$ overflow and its contribution to the global thermohaline circulation merits further studies, and requires more detailed knowledge of the deeper branch of the overflow and its path into the Iceland Basin. 
Appendix A: Mooring data

\section{A1 Instruments and data return}

Details of mooring positions and instrumentation are given in Table A1. The table also gives record lengths if they are shorter than the whole 1-year deployment, for example, in the case of the three ADCPs sampling at higher resolution (see Sect. 2).

\section{A2 Mooring movement and data interpolation}

The strong currents caused mooring knockdown, statistics of which are presented in Table A2. Mooring knockdown events led to tilting of the instruments, occasionally more than the threshold values for acceptable tilt specified by the manufacturers: $15^{\circ}$ for RDI-ADCPs and $12^{\circ}$ for RCMs. A gimbal on the RCM frame compensates for tilts of up to $27^{\circ}$, so the practical threshold limit is $39^{\circ}$. Data from periods with too large a tilt are excluded from the analysis, causing a slight bias towards lower velocities (since the drag and thus the tilt are larger for larger velocities). The percentage of data discarded for each instrument is listed in Table A2. 
Table A1. Mooring positions, instrumentation, and data return. The nominal depth level of each instrument is given as height above bottom, HAB (m). Temperature is measured at every level, and any additional parameters measured are indicated as follows: conductivity as underlined, pressure as bold, and velocity in square brackets. The full deployment length was 372 days; any shorter records are marked by superscripts and the record length given in the column on the right. For current profilers, the target range is shown in a separate column. Instrument types are abbreviated as follows: SBE37 (s37), SBE39 (s39), SBE56 (s56), Continental (con), downward-looking RDI (rdD), upward-looking RDI (rdU), Aquadopp (aqd), RCM-7 (rm7), and Seaguard (sea). Three of the short records (superscripts 3, 6, and 9) are from the downward-looking RDI ADCPs at moorings C2, M1, and S3, respectively, that were set at a higher sampling resolution.

\begin{tabular}{|c|c|c|c|c|}
\hline $\begin{array}{l}\text { Mooring } \\
\text { Depth }(\mathrm{m})\end{array}$ & $\begin{array}{l}\text { Lon. (W) } \\
\text { Lat. (N) }\end{array}$ & $\begin{array}{l}\text { Target } \mathrm{HAB}(\mathrm{m}) \\
\text { Instrument type }\end{array}$ & $\begin{array}{l}\text { Velocity } \\
\text { range }(\mathrm{m})\end{array}$ & $\begin{array}{l}\text { Data days } \\
(\text { if }<372)\end{array}$ \\
\hline $\mathrm{C} 1$ & $8^{\circ} 27.9^{\prime}$ & $10,30,40, \underline{\mathbf{5 0}}, 60,80, \underline{100}, 125, \mathbf{1 5 0}, 175^{1}, 200^{2},[\mathbf{2 0 2}]$ & $20-195$ & ${ }^{1} 204,{ }^{2} 152$ \\
\hline 650 & $61^{\circ} 40.4^{\prime}$ & $\mathrm{s} 56, \mathrm{~s} 56, \mathrm{~s} 56, \mathrm{~s} 37, \mathrm{~s} 56, \mathrm{~s} 56, \mathrm{~s} 37, \mathrm{~s} 56, \mathrm{~s} 39, \mathrm{~s} 56, \mathrm{~s} 37, \mathrm{con}$ & & \\
\hline $\mathrm{C} 2$ & $8^{\circ} 32.5^{\prime}$ & $\underline{\mathbf{2 5}},[\mathbf{2 7}], 50,75,100,125, \mathbf{1 5 0}, 175,200,[\mathbf{2 0 0}]^{3}, \underline{\mathbf{2 5 0}}, 300^{4}, 350,[\mathbf{4 0 1}]$ & $92-192$ & ${ }^{3} 120,{ }^{4} 301$ \\
\hline 807 & $61^{\circ} 37.4^{\prime}$ & $\mathrm{s} 37$, aqd, s56, s56, s37, s56, s39. s56, s56, rdD, s37, s56, s56, rdD & $15-367$ & \\
\hline $\mathrm{C} 3$ & $8^{\circ} 37.7^{\prime}$ & {$[25], \underline{27}, \underline{100}, 140,[150]^{5}$} & $14-142$ & $5_{234}$ \\
\hline 859 & $61^{\circ} 33.6^{\prime}$ & $\mathrm{rm} 7, \overline{\mathrm{s} 37}, \overline{\mathrm{s} 37}, \mathrm{~s} 39, \mathrm{rdD}$ & & \\
\hline M1 & $9^{\circ} 20.0^{\prime}$ & {$[25], \underline{\mathbf{2 7}}, 50,75, \underline{100}, \mathbf{1 2 5}, 150, \underline{\mathbf{1 7 0}},[\mathbf{1 7 5}]^{6}, 200,250, \mathbf{3 0 0}$} & $67-167$ & $6_{94}$ \\
\hline 808 & $61^{\circ} 45.0^{\prime}$ & 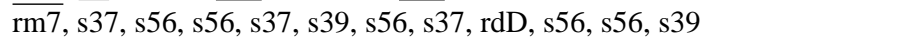 & & \\
\hline S1 & $9^{\circ} 29.0^{\prime}$ & {$[80]^{7}$} & & ${ }^{7} 371$ \\
\hline 610 & $61^{\circ} 54.9^{\prime}$ & $\mathrm{rm} 7$ & & \\
\hline S2 & $9^{\circ} 36.5^{\prime}$ & {$[25]^{8}, \underline{\mathbf{2 7}}, 50,75, \underline{100}, \mathbf{1 5 0}, 175, \underline{\mathbf{2 0 0}}, \mathbf{2 5 0},[275]$} & $34-258$ & $8_{371}$ \\
\hline 805 & $61^{\circ} 49.2^{\prime}$ & $\mathrm{rm} 7, \mathrm{~s} 37, \mathrm{~s} 56, \mathrm{~s} 5 \overline{6}, \mathrm{~s} 37, \mathrm{~s} 39, \mathrm{~s} 56, \overline{\mathrm{s} 37}, \mathrm{~s} 39, \mathrm{rdD}$ & & \\
\hline S3 & $9^{\circ} 43.2^{\prime}$ & $\begin{array}{l}{[25], \underline{\mathbf{2 7}}, \mathbf{5 0}, \underline{100}, 125, \mathbf{1 5 0},[\mathbf{1 7 5 5}]^{9}, 200, \underline{\mathbf{2 5 0}}, 300,350,400^{10},} \\
\left.450, \mathbf{5 0 0}^{11},[\mathbf{5 0 2}]^{12}, \mathbf{5 0 3}\right]\end{array}$ & $\begin{array}{l}67-167 \\
20-486\end{array}$ & $\begin{array}{l}{ }^{9} 109,{ }^{10} 326 \\
{ }^{11} 328,{ }^{12} 281\end{array}$ \\
\hline 950 & $61^{\circ} 43.6^{\prime}$ & $\begin{array}{l}\mathrm{rm} 7, \mathrm{~s} 37, \mathrm{~s} 56, \mathrm{~s} 37, \mathrm{~s} 56, \mathrm{~s} 39, \mathrm{rdD}, \mathrm{s} 56, \mathrm{~s} 37, \mathrm{~s} 56, \mathrm{~s} 37, \mathrm{~s} 56, \mathrm{~s} 56, \mathrm{~s} 56, \\
\mathrm{~s} 56, \mathrm{~s} 37, \mathrm{rdD}, \mathrm{rdU}\end{array}$ & $520-816$ & \\
\hline S4 & $9^{\circ} 49.1^{\prime}$ & {$[25]^{13}, \underline{\mathbf{2 7}}, \mathbf{5 0},[\mathbf{7 5}]^{14}, \underline{\mathbf{1 0 0}}, 125^{14},[\mathbf{1 5 0}], \mathbf{1 7 5}, 200^{14}, \underline{\mathbf{2 5 0}}, 299, \underline{\mathbf{3 0 0}}^{14}$} & & ${ }^{13} 1$ \\
\hline 1082 & $61^{\circ} 38.5^{\prime}$ & $\mathrm{rm} 7, \mathrm{~s} 37, \mathrm{~s} 56, \mathrm{rm} 7, \mathrm{~s} 37, \mathrm{~s} 39, \mathrm{sea}, \mathrm{s} 39, \mathrm{~s} 39, \mathrm{~s} 37, \mathrm{~s} 56, \mathrm{rm} 7$ & & ${ }^{14} 371$ \\
\hline
\end{tabular}

Table A2. Table showing maximum pulldown (from pressure sensors); percentage of time that pulldown is larger than 25,50 , or $100 \mathrm{~m}$, respectively; root mean square error $e$ of the pulldown from the recorded pressure and modelled with MDD (Dewey, 1999); and the percent data discarded for each velocity recording instrument, listed from bottom upwards for each mooring; cf. Table A1.

\begin{tabular}{cccccccccl}
\hline & $\begin{array}{c}\mathrm{HAB} \\
(\mathrm{m})\end{array}$ & $\begin{array}{c}\Delta H_{\max } \\
(\mathrm{m})\end{array}$ & $\begin{array}{c}\Delta H>25 \\
(\%)\end{array}$ & $\begin{array}{c}\Delta H>50 \\
(\%)\end{array}$ & $\begin{array}{c}\Delta H>100 \\
(\%)\end{array}$ & $\begin{array}{c}e_{25} \\
(\mathrm{~m})\end{array}$ & $\begin{array}{c}e_{50} \\
(\mathrm{~m})\end{array}$ & $\begin{array}{c}e_{100} \\
(\mathrm{~m})\end{array}$ & $\begin{array}{l}\text { Instr.:discarded } \\
(\%)\end{array}$ \\
\hline $\mathrm{C} 1$ & 150 & 16 & 0 & 0 & 0 & - & - & - & con:0 \\
$\mathrm{C} 2$ & 250 & 100 & 7.96 & 1.54 & 0 & 10 & 16 & 36 & aqd:0, rdD:2.7, rdD:2.6 \\
$\mathrm{C} 3$ & 140 & 54 & 4.06 & 0.01 & 0 & 2 & 3 & - & rm7:0, rdD:0 \\
$\mathrm{S} 2$ & 250 & 118 & 3.97 & 1.23 & 0.09 & 12 & 15 & 20 & rm7:0.3, rdD:0 \\
$\mathrm{S} 3$ & 500 & 141 & 4.49 & 1.22 & 0.12 & 24 & 40 & 76 & rm7:0, rdD:2.3, rdD:2.4, rdU:0 \\
$\mathrm{S} 4$ & 250 & 48 & 0.18 & 0 & 0 & 15 & - & - & rm7:0, rm7:0, sea:0, rm7:0 \\
\hline
\end{tabular}




\section{Appendix B: Transport calculation}

The volume transport of water in different temperature classes was calculated for mooring sections $\mathrm{C}$ and $\mathrm{S}$ as follows. Temperature and rotated velocity records were lowpass filtered with a third-order Butterworth filter with a $27 \mathrm{~h}$ cut-off period, and daily averages were computed. Depth levels with less than $70 \%$ good data were excluded. At moorings shorter than $300 \mathrm{~m}$, velocity and temperature profiles were extended to 300 mab using constant shear or a constant temperature gradient, respectively, above the top instrument (allowed to continue only to $0 \mathrm{~cm} \mathrm{~s}^{-1}$ or $8^{\circ} \mathrm{C}$ ). At $\mathrm{S} 1$, where there was only one instrument at $80 \mathrm{mab}$, velocity was set to decrease and temperature to increase linearly upwards to $0 \mathrm{cms}^{-1}$ and $8^{\circ} \mathrm{C}$, respectively, at $300 \mathrm{mab}$. At $\mathrm{C} 3$, the downward-looking ADCP at 150 mab failed after 234 days of recording (Table A1), on 17 January 2013. Rather than trying to construct velocity records for most of the water column at this important location after that, we choose to compute volume transports only for the period in which we have vertical velocity profile coverage of the high-velocity bottom layer of the plume at all three $\mathrm{C}$-array moorings. Velocities were linearly extrapolated downward to 0 at the bottom from the deepest instrument on each mooring. If this was located higher than 50 mab, velocity was kept constant from the deepest instrument down to 50 mab before decaying linearly from there to 0 at the bottom. Temperature was kept constant from the deepest instrument to the bottom. The resulting vertical profiles from all moorings on one array were then gridded onto a $5 \mathrm{~m}$ vertical by $1 \mathrm{~km}$ horizontal grid for each day using linear interpolation, with velocity set to 0 at the bottom grid point. To extend the section horizontally, data from the outer moorings in each array were kept constant to the sides over half the distance between moorings. The resulting gridded cross sections represent daily snapshots of the plume velocity and temperature structure. Volume transport in different temperature classes was estimated for each day by summing the transport contributions (the along-stream $u$ velocity component multiplied by the corresponding crosssectional area defined by the isotherms). Only $u \leq 0$ was included; any reverse flow was not included in the plume transport calculation.

Sensitivity to different methods of interpolating and extrapolating data to grids of varying resolutions was examined. Because the overflow is swift and the cross-sectional area is large, the results are not sensitive to the details of the choices for upper and bottom boundaries and plume edges. The transport obtained from the method described above ( $\left.Q_{\text {grid }}\right)$ was compared with those computed by two other methods (see Fig. B1). One method is to compute transport per unit width for each mooring, multiplying this by a representative width for each mooring, and then summing up the contribution of the individual moorings, as described in Darelius et al. (2011). This will be referred to as $Q_{\text {moor }}$. The other alternative method is to compute "kinematic overflow"

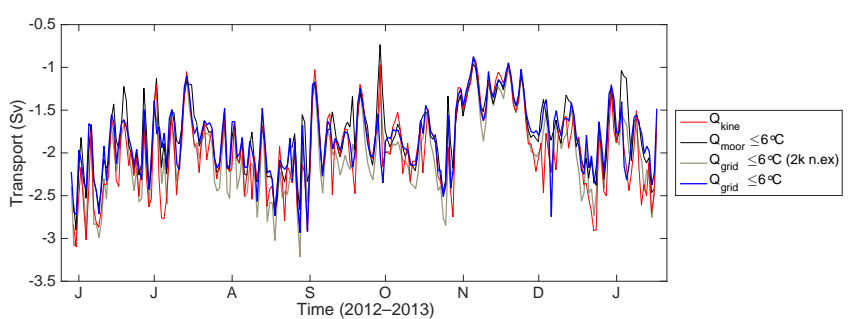

Figure B1. Time series of volume transport at mooring section $\mathrm{C}$ computed by different methods: kinematic ( $\left.Q_{\text {kine }}\right)$, per mooring ( $\left.Q_{\text {moor }}\right)$, and from gridded fields $\left(Q_{\text {grid }}\right)$. The latter two methods allow calculation of transport by temperature range, and results are shown here for the $\leq 6^{\circ} \mathrm{C}$ temperature class. The grey line represents a version with a $2 \mathrm{~km}$ horizontal grid and no upward extrapolation (which led to data from the longest, central mooring dominating the upper levels of the grid), and the blue line is the version used to produce the values of $Q_{\text {grid }}$ reported in Sect. 4 .

$\left(Q_{\text {kine }}\right)$, defined in Hansen and $\varnothing$ sterhus (2007) as the volume flux of water from the bottom up to the level at which the overflow velocity is reduced to half of the profile maximum. Changes in terms of vertical extrapolation and horizontal grid resolution had relatively small effects on the long-term mean values of transport from the gridded fields. The transport time series $Q_{\text {moor }}$ at C had a similar long-term mean and standard deviation for the temperature range $\leq 6{ }^{\circ} \mathrm{C}(1.8 \pm 0.4 \mathrm{~Sv})$ as

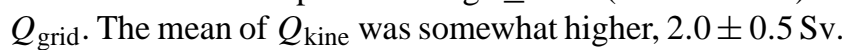
Similarly, Darelius et al. (2015) found that $Q_{\text {moor }}$ at array C was somewhat lower than (but correlated with) $Q_{\text {kine }}$ at the sill. Volume transports stated in the main body of this paper are $Q_{\text {grid. }}$. 
Acknowledgements. We thank the technicians involved in mooring preparation and deployment, H. Bryhni and S. Myking, and the crew of the RV Håkon Mosby. Thanks also to M. Hecht and two anonymous reviewers whose comments helped improve the manuscript. This work was funded by the Research Council of Norway through the FRINAT programme, under project no. 204867/V30: "Faroe Bank Channel Overflow: Dynamics and Mixing".

Edited by: M. Hecht

\section{References}

Beaird, N. L., Fer, I., Rhines, P., and Eriksen, C.: Dissipation of turbulent kinetic energy inferred from Seagliders: an application to the Eastern Nordic Seas overflows, J. Phys. Oceanogr., 42, 2268-2282, doi:10.1175/jpo-d-12-094.1, 2012.

Beaird, N. L., Rhines, P. B., and Eriksen, C. C.: Overflow waters at the Iceland-Faroe Ridge observed in multiyear Seaglider surveys, J. Phys. Oceanogr., 43, 2334-2351, doi:10.1175/JPO-D13-029.1, 2013.

Borenäs, K. and Lundberg, P.: The Faroe-Bank Channel deep-water overflow, Deep-Sea Res. Pt. II, 51, 335-350, 2004.

Borenäs, K. M. and Lundberg, P. A.: On the deep-water flow through the Faroe Bank Channel, J. Geophys. Res., 93, 12811292, 1988.

Borenäs, K. M., Lake, I. M., and Lundberg, P. A.: On the intermediate water masses of the Faroe-Bank Channel overflow, J. Phys. Oceanogr., 31, 1904-1914, 2001.

Chang, Y. S., Garraffo, Z. D., Peters, H., and Özgökmen, T. M.: Pathways of Nordic Overflows from climate model scale and eddy resolving simulations, Ocean Model., 31, 66-84, 2009.

Darelius, E., Fer, I., and Quadfasel, D.: Faroe Bank Channel overflow: mesoscale variability, J. Phys. Oceanogr., 41, 2137-2154, 2011.

Darelius, E., Ullgren, J. E., and Fer, I.: Observations of barotropic oscillations and their influence on mixing in the Faroe Bank Channel overflow region, J. Phys. Oceanogr., 43, 1525-1532, doi:10.1175/JPO-D-13-059.1, 2013.

Darelius, E., Fer, I., Rasmussen, T., Guo, C., and Larsen, K. M. H.: On the modulation of the periodicity of the Faroe Bank Channel overflow instabilities, Ocean Sci., 11, 855-871, doi:10.5194/os11-855-2015, 2015.

Dewey, R. K.: Mooring Design and Dynamics - a Matlab package for designing and analyzing oceanographic moorings, Marine Models, 1, 103-157, 1999.

Dickson, B., Yashayaev, I., Meincke, J., Turrell, W. R., Dye, S., and Holfort, J.: Rapid freshening of the deep North Atlantic Ocean over the past four decades, Nature, 416, 832-837, 2002.

Dickson, R. R. and Brown, J.: The production of North Atlantic Deep Water: sources, rates and pathways, J. Geophys. Res., 99, 12319-12341, 1994.

Dooley, H. D. and Meincke, J.: Circulation and water masses in the Faroese Channels during Overflow '73, Deutsche Hydrographische Zeitschrift, 34, 41-55, 1981.

Duncan, L. M., Bryden, H. L., and Cunningham, S. A.: Friction and mixing in the Faroe Bank Channel outflow, Oceanol. Acta, 26, 473-486, 2003.
Fer, I., Voet, G., Seim, K. S., Rudels, B., and Latarius, K.: Intense mixing of the Faroe Bank Channel overflow, Geophys. Res. Lett., 37, L02604, doi:10.1029/2009GL041924, 2010.

Fer, I., Peterson, A. K., and Ullgren, J. E.: Microstructure measurements from an underwater glider in the turbulent Faroe Bank Channel overflow, J. Atmos. Ocean. Tech., 31, 1128-1150, 2014.

Fogelqvist, E., Blindheim, J., Tanhua, T., Østerhus, S., Buch, E., and Rey, F.: Greenland-Scotland overflow studied by hydro-chemical multivariate analysis, Deep-Sea Res. Pt. I, 50, 73-102, 2003.

Geyer, F., Østerhus, S., Hansen, B., and Quadfasel, D.: Observations of highly regular oscillations in the overflow plume downstream of the Faroe Bank Channel, J. Geophys. Res., 111, C12020, doi:10.1029/2006JC003693, 2006.

Guo, C., Ilicak, M., Fer, I., Darelius, E., and Bentsen, M.: Baroclinic instability of the Faroe Bank Channel overflow, J. Phys. Oceanogr., 44, 2698-2717, 2014.

Hansen, B. and Østerhus, S.: North Atlantic-Nordic Seas exchanges, Prog. Oceanogr., 45, 109-208, 2000.

Hansen, B. and Østerhus, S.: Faroe Bank Channel overflow 19952005, Prog. Oceanogr., 75, 817-856, 2007.

Hansen, B., Turrell, W. R., and Østerhus, S.: Decreasing overflow from the Nordic seas into the Atlantic Ocean through the Faroe Bank channel since 1950, Nature, 411, 927-930, 2001.

Hermann, F.: The TS diagram analysis of the water masses over the Iceland-Faroe Ridge and in the Faroe Bank Channel, Rapp. PV Reun. Cons. Int. Explor. Mer., 157, 139-149, 1967.

Hogg, N., Biscaye, P., Gardner, W., and Schmitz Jr, W. J.: On the transport and modification of Antarctic Bottom Water in the Vema Channel, J. Mar. Res., 40, 231-263, 1982.

Høyer, J. L. and Quadfasel, D.: Detection of deep overflows with satellite altimetry, Geophys. Res. Lett., 28, 1611-1614, 2001.

Kanzow, T. and Zenk, W.: Structure and transport of the Iceland Scotland Overflow plume along the Reykjanes Ridge in the Iceland Basin, Deep-Sea Res. Pt. I, 86, 82-93, 2014.

Lake, I. and Lundberg, P.: Seasonal barotropic modulation of deep-water overflow through the Faroe Bank Channel, J. Phys. Oceanogr., 36, 2328-2339, 2006.

Lee, A. J.: Temperature and salinity distributions as shown by sections normal to the Iceland-Fareo Ridge, Rapp. PV Reun. Cons. Int. Explor. Mer., 157, 100-135, 1967.

Legg, S.: Overflows and convectively driven flows, in: BuoyancyDriven Flows, edited by: Chassignet, E., Cenedese, C., and Verron, J., Cambridge University Press, Cambridge, UK, 203-239, 2012.

Marshall, J. and Shutts, G.: A note on rotational and divergent eddy fluxes, J. Phys. Oceanogr., 11, 1677-1680, 1981.

Mauritzen, C., Price, J., Sanford, T., and Torres, D.: Circulation and mixing in the Faroese Channels, Deep-Sea Res. Pt. I, 52, 883913, 2005.

Müller, T. J., Meincke, J., and Becker, G. A.: Overflow'73: the distribution of water masses on the Greenland-Scotland ridge in August/September 1973; a data-report, Institut für Meereskunde an der Christian-Albrechts-Universität Kiel, 1967.

Prater, M. D. and Rossby, T.: Observations of the Faroe Bank Channel overflow using bottom-following RAFOS floats, Deep-Sea Res. Pt. II, 52, 481-494, 2005.

Price, J. F. and O'Neil Baringer, M.: Outflow and deep water production by marginal seas, Prog. Oceanogr., 33, 161-200, 1994. 
Riemenschneider, U. and Legg, S.: Regional simulations of the Faroe Bank Channel overflow in a level model, Ocean Model., 17, 93-122, 2007.

Saunders, P. M.: Cold outflow from the Faroe Bank Channel, J. Phys. Oceanogr., 20, 29-43, 1990.

Saunders, P. M.: The dense northern overflows, in: Ocean Circulation and Climate, Chap. 5.6, edited by: Siedler, G., Church, J., and Gould, J., Academic Press, London, UK, 401-417, 2001.

Seim, K. S., Fer, I., and Berntsen, J.: Regional similations of the Faroe Bank Channel overflow using a $\sigma$-coordinate ocean model, Ocean Model., 35, 31-44, 2010.

Swift, J. H.: The circulation of the Denmark Strait and IcelandScotland overflow waters in the North Atlantic, Deep-Sea Res., 31, 11, 1339-1355, 1984.

Tait, J. B. (Ed.): The Iceland-Faroe Ridge international (ICES) "Overflow" expedition, May-June, 1960, Rapp. PV Reun. Cons. Int. Explor. Mer., 157, 1-274, 1967.

Thorpe, S. A.: An Introduction to Ocean Turbulence, Cambridge University Press, Cambridge, UK, 2007.
Ullgren, J. E., Fer, I., Darelius, E., and Beaird, N.: Interaction of the Faroe Bank Channel overflow with Iceland Basin intermediate waters, J. Geophys. Res.-Oceans, 119, 228-240, doi:10.1002/2013JC009437, 2014.

van Aken, H. M.: The Oceanic Thermohaline Circulation. An Introduction, vol. 39 of Atmospheric and Oceanographic Sciences Library, Springer, New York, USA, 2007.

van Aken, H. and Becker, G.: Hydrography and through-flow in the north-eastern North Atlantic Ocean: the NANSEN project, Prog. Oceanogr., 38, 297-346, 1996.

Voet, G. and Quadfasel, D.: Entrainment in the Denmark Strait overflow plume by meso-scale eddies, Ocean Sci., 6, 301-310, doi:10.5194/os-6-301-2010, 2010.

Whitehead, J. A. and Worthington, L. V.: The flux and mixing rates of Antarctic bottom water within the North Atlantic, J. Geophys. Res., 87, C10, 7903-7924, 1982. 